\title{
PERSPECTIVAS DEMOCRÁTICAS DEL PROCESO DE INTEGRACIÓN EUROPEA
}

\author{
Mónica Fernández Gutiérrez*
}

SUMARIO: Introdución. A. Contexto global y entidades supranacionales. A.1. Evolución de las estructuras políticas: Del Estado al ente supranacional, pasando por las garantías individuales. A.2. Supranacionalidad y afectación democrática. B. Soberanía y pueblo en el contexto supranacional europeo. C. Proyecto constitucional de la Unión Europea y proceso de democratización. C.1. Convención, como mecanismo de legitimación democrática. C.2. Referencias a los aportes específicos del Proyecto de Tratado constitucional de la Unión Europea relacionados con el proceso democrático. C.3. Especial referencia a la Carta de derechos fundamentales como núcleo constitucional europeo. Breves conclusiones

RESUMEN: La importancia de la fenomenología jurídico-politica actual genera la necesidad de analizar el modo en el que nuevas formas de organización política, en particular la del Sistema de Integración de la Unión Europea en su estado de evolución constitucional, incide en la práctica democrática y en el respeto a los derechos fundamentales.

Palabras clave: Unión Europea - Globalización - Derechos fundamentales - Supranacionalidad - Democratización.

\section{INTRODUCCIÓN}

Uno de los fenómenos más relevantes vinculados al contexto general de la globalización/mundialización ${ }^{1}$, es el protagonizado por la supranacionalidad, sus formas y sus efectos, los cuales ofrecen un escenario par-

\footnotetext{
* Diplôme d'Université en Derecho comunitario del Instituto de Estudios Internacionales y europeos de la Sorbonne, Paris I: Magíster en Derecho comunitario por la Universidad Complutense de Madrid y por la Universidad de Castilla la Mancha. Suficiencia investigadora, Diploma de Estudios Avanzados (DEA) de Doctorado en Ciencia Jurídica, especialidad en Derecho Comunitario, UCLM.

** Esce trabajo forma parte del Proyecto interno DID, Código $N^{\circ} 2002-57$, de la Universidad Austral de Chile: La Democracia como categoría fundamentadora de los ordenamientos interno e internacional; el problema de la Democracia nacional y la Democracia global como principio legitimador:

1 Held, Di: La democracia global, Edit. Paidós, Estado y sociedad, 2002.
} 
ticularmente interesante para el despliegue de consecuencias sobre el modelo democrático.

Dentro de la multiplicidad de enfoques que abarca dicho fenómeno, los sistemas de integración ${ }^{2}$ aparecen como formas organizativas que sitúan al fenómeno democrático en un contexto experimental destinado a adaptarse a la realidad existente.

El sistema de integración de la Unión Europea (UE) por constituir el parámetro más avanzado de sistema de integración de Estados, posibilita el análisis de las consecuencias que las exigencias actuales plantean a la capacidad de evolución de los sistemas jurídico-políticos.

Dentro de este contexto, destaca la relevancia del actual proceso de constitucionalización, protagonizado por el Proyecto de Tratado, por el que se pretende instituir una Constitución para la UE, el cual incluye la estructuración de las relaciones entre el individuo y la nueva estructura de poder, afectando directamente al concepto de democracia.

\section{A. CONTEXTO GLOBAL Y ENTIDADES SUPRANACIONALES}

A lo largo de la historia, la necesidad de adaptación ha llevado al hombre y a sus instituciones a ir cambiando y modificando las estructuras organizativas creadas para dar respuesta a los diversos acontecimientos que se producen en el espacio y el tiempo donde se encuentra inmerso.

Un acercamiento a la fenomenología jurídico política actual, sitúa al Estado y al individuo en un panorama global donde las esferas de poder llevan irremediablemente a tener en cuenta un gran cúmulo de elementos que interactúan entre sí, sin estructura democrática de gobierno proporcional a los efectos que se producen, generando un escenario particularmente complejo, donde el riesgo de aumentar el distanciamiento de las relaciones individuales de las estructuras de poder puede verse incrementado, de no establecerse los necesarios medios de control del mismo.

Actualmente la forma de institucionalización del Estado-nación presenta las consecuencias de la la creciente presión de la "globalización"3 (concepto que en sí mismo, entraña a su vez conflictos conceptuales ${ }^{4}$ ), y de la respectiva reacción de ciertos Estados a la misma.

2 Vid. Alonso Garcia, R.: Derecho comunitario, Derechos nacionales y Derecho europeo. Edit. Civitas, vid. de la autora de este artículo, "Aspectos fundamentales del sistema de integración de la Unión Europea. Referencias al MERCOSUR", en Revista de la Escuela de Derecho 2001, N² 2, Universidad Católica de Temuco. Chile.

3 Para otros autores, con ciertas diferencias de enfoque mundialización, vid. Held (n. 1).

4 Vid. Habermas, J.: La Constelación Posnacional, Edic. Paidós, Año 2000; vid. Giddens, A.: Consecuencias de la modernidad, Alianza, 1993.; vid. VAllespin, F.: El futuro de la politica, Taurus, 2000; vid. Manuel CAStel.s., El fin del milenio, 1998, Alianza, como el de la sustitución de global por regional, en lo que a capitalismo liberal se refiere, como le ocurren a los conceptos de democracia y derechos humanos y su universalización. 
Dicha expresión es empleada por parte de HABermas para la descripción de un proceso, no de un estado final, el cual se caracteriza por el creciente volumen e intensidad del tráfico, la comunicación y los intercambios más allá de las fronteras nacionales ${ }^{5}$, conformándose un escenario dominado por un mercado ${ }^{6}$, que impone sus propias pautas de gobierno de forma transversal, en base, en principio, al fin último de elevación de la calidad de vida de los individuos y de los Estados.

Otros autores hacen referencia ${ }^{7}$ a la progresiva extensión de las formas de relación y organización social, que desbordan las estructuras tradicionales y se expanden en proporciones esféricas ${ }^{8}$, o como establece O'BRIAN, cuando se refiere al fin de la geografía, y a las interacciones que crean nuevas redes de acción globalizada ${ }^{9}$, que vincula a su vez al factor local de dicho fenómeno ${ }^{10}$.

Ambos conceptos, lo global y lo local, se encuentran directamente vinculados con la realidad democrática ${ }^{11}$, interactuando continuamente, como lo demuestran los efectos de vaciamiento de las relaciones individuales provocados por las consecuencias de la globalización ${ }^{12}$.

Por lo que la realidad actual no parece favorecer la cuestión pendiente del distanciamiento progresivo entre el individuo y las estructuras de poder resultante a nivel global, requiriéndose de un desarrollo democrático que pueda garantizar jurídica, política, social y culturalmente que el fenómeno global pueda ser sometido a las estructuras de control democráticas.

Por dicha razón, conviene poner especial atención al fenómeno del sistema supranacional de integración, como estructura jurídico-política, resultante de las necesidades de carácter supraestatal, como mecanismo abierto y en proceso de definición permanente, concebido para responder a una serie de necesidades y exigencias estatales e individuales, el cual parte del modelo democrático para intentar hacer frente en la medida de lo posible a los macro-efectos de la globalización ${ }^{13}$, que configuran, a su

5 Habermas: (n. 4), p. 91; vid. R. Cox, "Democracy in Hard Times", en: McGrew (comp.), Globalization and Territorial Democracy, p. 55.

6 Ibídem, p. 104; vid. R. W. Cox, "Global Restructuring: Making Sense of the Changing International Economy", en R. Stubbs, G. Underhill (comps.), Political Economy and the Changing Global Order, Nueva York, 1994, pp. 45-59.

Vid. VAllespin: (n. 4); vid. Giddens: (n. 4).

GidDens: (n. 4), p. 68

Vid. O'BRIAN, R.: The end of the Geographie; Londres, Rotledge, 1992; vid. Vallespin: (n. 4), p. 33.

Vid., GIDDENS: (n. 4), p 67.

Vid. BobBio, N.: El futuro de la democracia, Plaza y Janés, 1985.

Grupos de interés, de poder, trasnacionales que imponen las directrices económicas o políticas de acción a los gobiernos, por encima de cualquier tipo de control, desvinculación individuo y procesos políticos estatales, internacionales, supranacionales, etc.

Vid. VALLESPIN: (n. 4), p. 57. 
vez, un espacio global ${ }^{14}$, sin medidas de control proporcional a los efectos que esta produce, no implicando per se, una mayor asimilación y desarrollo democráticos ${ }^{15}$.

\section{A.1.Evolución de las estructuras políticas: Del Estado al ente su- pranacional, pasando por las garantías individuales}

Por lo que concierne a la evolución del Estado y de sus relaciones internas e internacionales, nuevos conceptos han venido a intentar satisfacer nuevas necesidades, y sin miedo a equivocarse, se puede afirmar actualmente que las grandes cuestiones que preocupan a los Estados y a los individuos no pueden encontrar una solución en un escenario únicamente circunscrito al contexto estatal ${ }^{16}$.

Como mantiene dicho autor, a nivel regional, internacional y global han surgido "formas de gobierno" 17 que hacen posible "un gobierno más allá del Estado-nación" y compensan, por lo menos parcialmente, la pérdida de capacidad en determinados ámbitos funcionales a nivel nacional, pueden llegar a otorgar repuesta a las necesidades surgidas como consecuencia de las relaciones de interdependencia a nivel internacional de los Estados ${ }^{18}$.

Dicha realidad repercute en el Estado, que ha de adaptar su realidad interna, para cohabitar armónicamente con un sistema supranacional que por encima de los intereses meramente estatales actúe en función de unos intereses comunes respecto de los que no se quiere o no se puede renunciar.

La tendencia actual debiera estar en posibilitar objetivos supranacionales ${ }^{19}$, adaptados al dinamismo de las necesidades, combinando la pervivencia del Estado nacional como base de la organización política de los países y de la propia organización internacional ${ }^{20}$.

\footnotetext{
14 Ibídem.

15 Vid. Vallespin: (n. 4), p. 71.

16. Sucesos ocurridos como los vividos por USA el 11 de sepriembre de 2001 a consecuencia del terrorismo internacional, o las consecuencias jurídicas, económicas, sociales y culturales de la inmigración en Occidente, reflejan realidades supraestacales, para las cuales se requiere de una acción conjunta...

17 Vid. Lehuedé Chaparro, H.: La Supranacionalidad, Editorial Jurídica de Chile, 1966. Asimismo, dicha fórmula presenta tres principios sobre los que se puede identificar la gestación del concepto, el bien común, como finalidad y componente esencial la soberanía, y respecto al ámbito espacial y cultural, un ámbito geográfico bomogéneo y un material bumano con rasgos culturales comunes, como requisitos esenciales de la supranacionalidad.

18 Habermas: (n. 4), p. 90.

19 Vid. Proyecto de Tratado constitucional, CONV. 724/03, 725/03, 810/03 en www. europa.eu.int

20 Vid. Kelsen, H.: Teoría General del Derecho y del Estado, Editorial Universidad Nacional Autónoma de México, 1979; vid. Cuestionamientos en torno a la idea de federación, como los surgidos en el proceso constitucional del Proyecto anteriormente mencionado, vid. CONV. $528 / 03$.
} 
En la actualidad se constata la necesidad de la actuación conjunta, desde la dirección de instituciones independientes de los Estados, así como a un derecho común o comunitario ${ }^{21}$ a todo ellos, que a su vez limita su libertad soberana, con el objetivo del cumplimiento de expectativas comunes, circunscritas a campos de aplicación, previamente pactados y establecidos por los mismos Estados.

Dicha necesidad viene determinada por el hecho de que los límites en la actual realidad mundial se encuentran desdibujados, puesto que las consecuencias siguen un ciclo que desconoce los espacios y tiene repercusiones en el tiempo, tanto de forma simultánea como de forma asincrónica ${ }^{22}$.

De acuerdo con dicha idea, HABERMAS afirma que "los poderes capaces de acción a nivel global no operan ya en el Estado de naturaleza del derecho internacional clásico, sino al nivel intermedio de una política mundial en vías de formación"23.

Ya H. KelSEN plantea en su momento, que "si se quiere mantener la tesis de una multiplicidad de comunidades jurídicas coordinadas entre ellas y consideradas como Estado, es preciso renunciar a la soberanía concebida como propiedad de cada Estado y admitir la idea de un orden jurídico internacional, que se encuentre por sobre todos ellos y mediante el cual, se coordinen, delimitando sus respectivas esferas de competencia", poniendo de relieve la situación de creciente relevancia de los sistemas de integración, señalando que "cada vez hay más instituciones ${ }^{24}$ interestatales que son manifestación de comunidades supranacionales en materia de legislación, jurisdicción y administración"25.

Por la envergadura de dichos acontecimientos, se podría afirmar que "la época contemporánea se ha caracterizado por presentar al hombre imbuido de una auténtica voluntad de cambio, la que se gestó luego de

21 Derecho comunitario europeo y para algunos autores, el proceso protagonizado por el Sistema de Integración del Mercosur, vid. el enfoque de F. GonzÁlez ODELKop. Sin embargo, el problema está en la fijación del criterio de diferenciación en la definición de los que supone el derecho supranacional, en el que desde la perspectiva europea, no es comprensible, sin la efectividad de ciertos principios rectores, como son la aplicabilidad directa y la primacía de dicho Ordenamiento sobre los Ordenamientos nacionales. tiembre de 2001 en EE.UU., han tenido repercusiones en las bolsas de comercio y en las economías del mundo en su toralidad, no solo en esos momentos, sino en el contexto de las consecuencias sucesivas que se van originando, sin importar el estado. Otra perspectiva con un origen similar la constituyen los flujos migratorios en masa, o las repercusiones medioambientales, los cuales constituyen fenómenos de tal envergadura que requieren un nuevo tipo de soluciones, que pasan obligatoriamente por la supranacionalidad y por la consecuente delegación de soberanía que ella lleva aparejada.

24 Vid. ibídem.

25 Ibidem. 
su convencimiento íntimo acerca de los verdaderos valores de su ordenación y de la finalidad que él persigue" 26 .

Sin embargo, la imperante necesidad de mutación y la velocidad exigida para la adaptación a tales cambios, repercute en elementos esenciales de la institucionalidad democrática, en sus relaciones intra y extra estatales poniendo en evidencia, la necesidad de situar al individuo como protagonista principal de las consecuencias últimas de esta evolución. Por lo que en este contexto el fenómeno supranacional ${ }^{27}$, vinculado a los procesos de integración, presenta una importancia decisiva e innovadora para el análisis de la fenomenología democrática ${ }^{28}$.

Una aproximación conceptual desde la perspectiva de la experiencia europea al carácter supranacional, se presenta vinculada desde el origen al fenómeno económico establecido por el libre mercado, basada en la decisión estatal voluntaria (en mayor o menor medida si se examina el carácter imperativo de la decisión) de transferir parte de su soberanía 29 para la consecución de los fines que pretendan llevar a efecto, comúnmente y de forma efectiva, en un proceso de integración progresivo que abarca cada vez mayor número de ámbitos materiales, regulándolos y haciéndose aplicable y exigible directamente tanto a los Estados, como a los individuos.

En este sentido, como límite de los efectos determinados por las fuerzas existentes que afectan tanto al Estado, como al individuo ${ }^{30}$, estas han de encontrar su fundamento último, en el interés generalizado de la

26

\section{Ibídem}

Sobre la situación de la Constitución chilena ante el fenómeno supranacional, vid, al respecto de la autora de este artículo "Límites constitucionales sobre la aplicación del Derecho comunitario en el Sistema de Integración europeo. Algunas referencias a la Constitución chilena de 1980", Jornadas de Derecho Público, Revista de Derecho. Universidad Católica de Valparaíso, Chile, 2002.

Vid. Habermas: (n. 4); vid. Teló, Mario, Aa.Vv.: "Democratie et construction européenne", Direction Mario Teló, Editions de l'Université de Bruxelles, Études Europeenes. Democratie internationale et democratie supranationale en Europe.

KELSEN: (n. 20).

El Estado nacional ha reconocido ya en efecto y no solo en Europa occidental, sus limitaciones para continuar cumpliendo satisfactoriamente todas sus misiones, en particular la de asegurar el nivel y la calidad de vida en el mundo actual, y ha accedido e incluso promueve activamente, la superación de sus carencias mediante la integración en instancias más amplias supranacionales, en PAREjo Alfonso, Ortega Álvarez, Jiménez Blanco: Manual de Derechos Administrativo. Parte general, Editorial Ariel, 5 " edición, 1998. Respecto de la situación actual, dichos autores opinan que "se trata de un movimiento lógico de salida de la crisis y de desorientación e incertidumbre en el ámbito de la economía. Esa misma lógica determina una tendencia paralela pero de distinto signo, el repliegue a comunidades más pequeñas y reconocibles (...), lo que tiene una importancia relevante en nuestro Estado autonómico (...). El Estado en su forma tradicionalmente establecida, atraviesa una crisis (...), que traduce una exigencia de transformación de este. Debe tenerse en cuenta que el Estado nacional viene siendo y es sujeto activo protagonista de la integración supranacional, y además, marco de ordenación y de integración en el 
mejora de vida de los individuos ${ }^{31}$ y de sus pueblos, en el sentido que plantea Ferrajoli, el cual entiende que "la soberanía externa del Estado, deja de ser absoluta para quedar subordinada jurídicamente a dos normas fundamentales, el imperativo de la paz y la tutela de los derechos humanos" 32 , factores inherentes a la concepción de democrática, concepción a la que deben quedar sometidas este tipo de relaciones y de la cual se espera un desarrollo de acuerdo a las necesidades emergentes.

Asumiendo que el proceso supranacional ${ }^{33}$ se presenta unido irremediablemente al hecho de que "los poderes capaces de acción a nivel global no operan ya en el Estado de naturaleza del derecho internacional clásico, sino al nivel intermedio de una política mundial en vías de formación" ${ }^{34}$, en torno a la búsqueda en último término, de la elevación de la calidad de vida del individuo, se está requiriendo en la actualidad de una nueva estructuración jurídica, conllevando una reforma de primera envergadura de la institucionalización de la sociedad internacional, que implica la adaptación de las estructuras existentes, en miras de perseguir los objetivos atinentes a este.

mundo supranacional e internacional de las comunidades políticas incernas (...). Por tanto, el panorama que se dibuja consiste más bien en la ampliación y diversificación de la estatalidad (en el sentido de poder político o público), y de los planos de afinidad e integración colectivos, en el que tiene asiento propio-reconvertido- la vieja instancia estatal nacional, en convivencia plausible tanto con las territoriales internas revalorizadas, como con las nuevas supranacionales". Ibídem.

31 En este contexto cabe hacer referencia a la interdependencia que ha surgido no solo entre Estados, sino entre los individuos, los cuales se caracterizan, cada vez más, por manifestar comportamientos comunes, que son consecuencia directa del proceso de mundialización o también llamado de globalización.

\section{Ibídem.}

33 Vid. de la autora de este artículo, "Aspectos fundamentales del sistema de integración de la Unión Europea. Referencias al MERCOSUR", Revista de la Escuela de Derecho, 2001, N ${ }^{\circ}$

2, Universidad Católica de Temuco, Chile.

34 "Esta polírica ofrece la imagen dinámica de interferencias e interacciones entre los caprichosos procesos políticos que transcurren a nivel nacional, internacional y global. Los sistemas internacionales de negociación, que hacen posibles los acuerdos entre los actores estatales se comunican, por una parte, con los procesos en el interior del Estado de los que dependen los respectivos gobiernos, pero, por otra, los adaptan al marco político: de la organización mundial. De esta forma, por lo menos, surge la perspectiva de una política interior mundial sin gobierno mundial, presuponiendo que se logre claridad sobre dos problemas. Uno es un problema de principios y el otro de naturaleza empírica. a) ¿Cómo es posible una legitimación democrática de las decisiones más allá de esquema de organización estatal? $\mathrm{Y}$ b), ¿bajo qué condiciones puede transformarse rápidamente la autocomprensión de los actores capaces de acción global, de forma que los Estados y los sistemas supranacionales se entiendan cada vez más como miembros de una comunidad que como tales no tienen más alternativa que una consideración de sus recíprocos intereses y una defensa de los intereses generales?", HABERMAS (n. 4), p. 142. 


\section{A.2. Supranacionalidad y afectación democrática}

Si bien el debace doctrinal sobre el alejamiento del individuo de las esferas de poder constituye una cuestión permanentemente abierta dentro de la ciencia política, la Unión Europea, en tanto que estructura supranacional de poder, se presenta como un escenario ad boc para el análisis de los efectos generados para la concepción de la democracia.

Dicha entidad se encuentra directamente concernida por la evolución del proceso democrático a la hora de analizar la compatibilidad del proceso supranacional con la adecuación progresiva de las relaciones entre individuo y el aparato de ejercicio de poder, que a este nivel se basa, a su vez, en el compromiso de la consolidación del Estado democrático de Derecho (Comunidad democrática de derecho), vinculado igualmente por el compromiso del respeto a los derechos humanos.

El acercamiento al estado de desarrollo democrático del sistema de integración de la UE, pasa obligatoriamente por el análisis de elementos propios, entre los cuales destacan la articulación de un sistema mixto que comparte aspectos supranacionales e intergubernamentales, sobre la base de un Ordenamiento jurídico dotado de primacía sobre el resto de Ordenamientos que la componen y de eficacia directa ante los Estados y los particulares, ${ }^{35}$ estructura que despliega una multiplicidad de efectos en sus diferentes niveles (supranacional, estatal y local) donde la dinámica democrática resulta directa e indirectamente repercutida ${ }^{36}$.

Así, a pesar de conservar importantes elementos de intergubernamentalidad $^{37}$, limitados a la cooperación mayor o menor entre los Esta-

is Vid. encre otros autores ALONSO GARCfA, R.: Derecho comunitario, Derechos nacionales y Derecho europeo, Cívicas; GIL IBÁN̄EZ, A. J.: El control y ejecución del Derecho comunitario, MAP, Instituto Nacional de Administraciones Públicas, Estudios jurídicos, Madrid, 1998; ISAAC, GUY: Manual de Derecho comunitario general, 4" edición, Edicorial Ariel S.A., Barcelona; MANIN, PH.: Les communautes Europeennes. L'Unión Europeenne. Droit institutianel, Editions Pedone, Paris, 1997. Vid. Parejo Alfonso, L; Jiménez-Blanco, A; Ortega Álvarez; (n. 30 ).

37 Concepto entendido como marco en el que se dan relaciones entre las voluntades estatales, que cooperan internacionalmente, en torno a ciertos objetivos, conservando su soberanía o independencia. En este contexto se enmarcan los pilares o ámbitos no comunitarios que integran la Unión Europea, y la práctica totalidad de las relaciones internacionales entre los Estados. 
dos, estos ámbitos sin delegación de soberanía, sin embargo, van progresivamente reduciéndose en favor de una integración más amplia, profun$\mathrm{da}^{38}$ y con un alto componente de irreversibilidad ${ }^{39}$.

De acuerdo con la concepción de entender la supranacionalidad como un concepto puesto al servicio del interés general de los Estados miembros ${ }^{40}$ y consecuentemente de sus ciudadanos, sin embargo dicha pretensión no parece posible sin el establecimiento de los mecanismos necesarios de respuesta fiscalizadora del desarrollo mismo de la integración.

El modelo de integración europeo, estructurado en base al Derecho comunitario, surge como un ente jurídico, creado en función de una delegación de competencias con base constitucional, en favor de una estructura supraestatal, que mantiene elementos propios del Estado e incorpora otros ajenos a aquel, dando lugar a una estructura orgánica específica y compleja ${ }^{41}$, en constante evolución.

38 Aunque a distintas velocidades de nivel y ritmo de integración. Vid. Tratados constitutivos TCE, Acta Única Europea, Tratado de la Unión Europea, Maastricht, Tratado de Amsterdam, Tratado de Niza, y actual Proyecto de Tratado Constitucional en proceso de negociación. Vid. www.europa.eu.int. Vid, se caracteriza por ejemplificar el sistema supranacional de integración que conforman hasta la fecha los quince Estados europeos: Francia, Bélgica, Holanda, Luxemburgo, Alemania, Reino Unido, Italia, Irlanda, Dinamarca, Grecia, España, Portugal, Austria, Suecia y Finlandia. A partir de mayo de 2004, se incorporan de pleno derecho los Estados de la próxima ampliación de la Unión: Polonia, Hungría, República Checa, Eslovaquia, Eslovenia, Estonia, Lituania, Letonia, Malta y Chipre.

39 Hasta la fecha, no había sido contemplada la posibilidad de dejar de ser parte de la Unión Europea. Sin embargo, actualmente se encuentran vigentes desde el Tratado de Amsterdam, procedimientos de sanción política habilitados al efecto, que posibilitan la suspensión de los derechos y beneficios de los Estados cuando estos incurran en una serie de supuestos que afectan frontalmente al Sistema de integración.

ju La integración será supranacional o intergubernamental, en virtud de la existencia de aspectos como el de la delegación de soberanía a favor de instituciones independientes, factores que serán vistos a continuación.

A propósito de la discusión sobre la autonomía del Derecho comunitario, vid. ISAAC, Guy: Manual de Derecho comunitario general, 4" edición, Editorial Ariel S.A., Barcelona, p. 190. Si bien conviene señalar al respecto, en una intervención en los debates del 12 de marzo de 1986 de la Conferencia de Viena sobre Derecho de los Tratados entre Estados y Organizaciones Internacionales o entre Organizaciones Internacionales, como destaca A.A. CANÇADO TRINDADE, "la manifiesta incompatibilidad con el concepto de jus cogens de la concepción voluntarista del derecho internacional, como manifestación de un positivismo jurídico anacrónico y degenerado. En efecto, tal concepción se mostró incapaz de explicar siquicra la formación de reglas del derecho internacional general y la incidencia en el proceso de formación y evolución del derecho internacional contemporáneo de elementos independientes del libre arbitrio de los Estados" (Vid. Cf. UN., United Nations Conference on the Law of Treaties between States and International Organizations or between International Organizations (Viena, 1986) - Official Records, vol. 1, N.Y., U.N., 1995, pP. 187-188 (intervención de A.A. CANÇADO TRINDADE, también reproducida en: 69171 Boletim da Sociedade Brasileira de Direitro International (1987-1989), pp. 283285, p. 417) A.A. CANÇADO TRINDADE: "Retos y perspectivas de la protección internacional de los Derechos Humanos al inicio del siglo XXI", en El Derecho internacional de 
De acuerdo a la afirmación de Jiménez Piernas, este elemento de supranacionalidad "se manifiesta asimismo, en numerosos elementos estructurales del sistema. En este sentido, factores como la aplicabilidad inmediata del mismo, vinculada directamente a su vez a la afirmación de primacía respecto a los derechos nacionales, de su capacidad de efecto directo, o en la jurisdicción obligatoria del Tribunal de Justicia de las Comunidades Europeas, constituyen todas ellas, consecuencias derivadas directamente de la delegación realizada por parte de los Estados, a favor de la organización supranacional, de manera voluntaria y conforme a los presupuestos propios que en cada Estado esté previsto a tal fin" ${ }^{\prime 2}$.

Fundamentalmente en razón de dichas particulares, dicho Ordenamiento fue definido como autónomo, como mantiene M. TELó ya "desde

los derechos bumanos en el siglo XXI, Capítulo VIII; vid. JIMÉnez PIERnAs, Carlos: "E1 Incumplimiento del derecho comunitario por los Estados miembros cuando median actos de particulares", en Revista de Derecho Comunitario Europeo, Vol.7 año 2000, pp. 15-48; Vid. Diez-Hochleintner, J:: "La interdependencia entre el Derecho Internacional y el Derecho de la Unión Europea", en Cursos de Derecho Internacional de Victoria-Gasteiz, 1998, introducción (pp. XXIII-XXVI); RODRígueZ IGLESIAS, G. C.: "Consideraciones sobre la formación de un Derecho Europeo", en CJ, No 200 Abril/Mayo 1999, 11-25, pp, 12-13; y Diez-Hochleintner: (n. 41), pp. 62-65: Sentencia TJCE. Molkerei, 3/04/68. En referencia a lo afirmado, hay que decir que, sin embargo, ciertas fuentes comunitarias requieren de un procedimiento de transposición posterior, como es el caso de las directivas, las cuales son el instrumento "legislativo" más utilizado del ordenamiento comunitario. Revista de Derecho Comunitario Europea, $N^{\circ} 7$, enero/junio de 2000, p. 17; a pesar, entre otras razones, de partir de una base fundada sobre los tratados internacionales, a excepción de los Tratados constitutivos mismos, reposan sobre una elaboración institucional y no consensual, la práctica totalidad de sus disposiciones están contenidas en derecho escrito, la totalidad del Derecho comunitario tiene reconocido de forma general la capacidad de ser de aplicación directa tanto a los Estados como a las personas y su primacía respecto de los ordenamientos nacionales, como factores determinantes de separación de la concepción puramente internacionalista.

Jiménez Piernas: (n. 41), Sentencia Costa. TJCE, 15/07/64, 6/64, 1141; Sentencia TJCE, Van Gend En Loos, 5/02/63, 26/62,1.

En este punto vid. MANIN, Ph.: (n. 35), p. 305. Respecto de la integración, JiméneZ PIERNAS (n. 41) señala, sin embargo, que a pesar de las diferencias del sistema comunitario, "el Derecho internacional público, está en el mismo origen del Derecho comunitario, ya que la constitución material de las Comunidades Europeas como una Comunidad de Derecho, ha cristalizado en un conjunto de Tratados cuya interpretación y aplicación sigue siendo también materia propia del Derecho internacional y de los respectivos ordenamientos consticucionales, al menos mientras los Estados soberanos sigan detentando el poder constituyente en la Comunidad", así como por la importancia del marco en el que se celebran las relaciones exteriores de las Comunidades Europeas.

Revista de Derecho Comunitario Europeo, $\mathrm{N}^{\circ} 7$, enero-junio de 2000, p. 17; a pesar, entre otras razones, de partir de una base fundada sobre los tratados internacionales, a excepción de los Tratados constitutivos mismos, reposan sobre una elaboración institucional y no consensual, la práctica totalidad de sus disposiciones están contenidas en derecho escrito, la totalidad del Derecho comunitario tiene reconocido de forma general la capacidad de ser de aplicación directa tanto a los Estados como a las personas y su primacía respecto de los ordenamientos nacionales, como factores determinantes de separación de la concepción puramente internacionalista. 
1964, el Tribunal, sobre la base del principio de uniformidad (art. 177), produce lo que WerLer llama una verdadera revolución jurídica, de aplicación a veces difícil, teniendo en cuenta las diferentes tradiciones constitucionales de los Estados miembros, el principio de competencia exclusiva, en lo que concierne a las materias previstas por el tratado" 43 .

Sin embargo, aunque este fenómeno produce nuevas estructuras, el ente supranacional resultante sigue encontrando su base en el modelo estatal, el cual en última instancia mantiene la protección de los intereses del individuo ${ }^{44}$ como elemento vertebrador de su ordenación, sometida al objetivo de construcción de una Comunidad democrática de Derecho, que congregue en base a unos parámetros de comportamiento político y reglas jurídicas comunes, una asociación de Estados, con sus respectivos administrados, capaces de estructurarse en torno a las necesidades globales surgidas, sin perder las características esenciales irrenunciables propias de las estructuras estatales de sus Estados miembros, e intentar innovar mejorando los canales de relación entre el poder público y los ciudadanos.

Dicha condición derivada del parámetro democrático y de la sumisión a Derecho, con el individuo y sus prerrogativas a la cabeza, han de ser permanentemente tenidas en cuenta como condición imprescindible para la consolidación del proceso político en curso, que a escala supranacional, corre el peligro de la generación automática de efectos, que pueden resultar perversos para el mantenimiento de la democracia.

El contexto globalizador, reflejado entre otros factores por el poder de las estructuras transnacionales $\mathrm{creadas}^{45}$, de los grupos de poder independientes, como el lobby empresarial ${ }^{46}$ o el científico, por los que pasa el juego de la toma de decisión política de los gobiernos, estatales o supranacionales, escapando al necesario control propio del sistema demo-

43 Como la política comercial, ibídem.

44 Vid. artículo 2 del Proyecto de Tratado por el que se instituye una Constitución, vid. Publicación oficial de la Convención, de 18 de julio de 2003.

45 Habermas: (n. 4), p. 136, plantea en este sentido la cuestión de los actores políticos en el marco de la ONU, la primera red de estructura débil para arreglos internacionales, podrían reforzar su laxa estructura de forma que fuera posible un cambio de rumbo hacia una política interior mundial sin gobierno mundial. Es interesante en este contexto destacar el interés que despierta la posibilidad de reconsiderar el papel de la ONU, en el sentido de encontrar en ella el ente supranacional que posibilite el tipo de soluciones internacionales que respecto a ciertos ámbitos de interés global parece poder requerirse. Según el autor, con todo, las agrupaciones supranacionales de este tipo cumplen una condición que es necesaria para la recuperación de la política frente a los mercados globalizados. De esta forma, por lo menos, podría formarse un grupo de actores cuya capacidad de acción tuviera un alcance global, es decir, que no solo fueran capaces de llegar a acuerdos decisivos, sino también capaces de llevarlos a cabo.

46 En el contexto europeo, las libertades establecidas por tratado para desarrollar el Mercado único (mercancías, servicios, personas, capitales). 
crático ${ }^{47}$, constituyen un potencial multiplicador de efectos negativos a la hora de afrontar el modelo político actual.

Factores como el avance de la globalización y la regionalización y el impacto del comercio internacional no tienen por menos que terminar incidiendo en los sistemas jurídicos-políticos ${ }^{48}$, requiriendo de medidas de salvaguardia para su adaptación, con las menores repercusiones ${ }^{49}$, requiriéndose de una respuesta que pueda sustentarse tanto en el presente como respecto del fucuro que llega, basada en la estructuración de un marco jurídico-polírico adaptado a las necesidades crecientes, manteniendo a las mismas personas como partes integrantes principales del sistema ${ }^{50}$.

En este contexto, los compromisos indelegables de los Estados por dar cumplimiento al contenido de las exigencias del Estado Democrático de Derecho, mediante el despliegue del carácter universalizador ${ }^{51}$ de los derechos humanos y su insustituible esfera de protección individual, suponen la premisa incondicional de la entidad política supranacional ${ }^{52}$.

47 En este sentido, las críticas al vaciamiento democrático producido por el poder desplegado por las multinacionales, otros lubbies de poder, científicos, tecnócratas, que en última instancia establecen unas pautas de acción, que escapan al control propio del Estado democrático. Desde una perspectiva estructural del sistema de integración europeo, numerosas críticas han sido vertidas en contra del déficit democrático de la Unión, el cual constituye uno de los caballos de Troya permanentes de las políticas internas de esta, en miras a ir reduciéndolo en la medida de lo posible.

48 LÓpez AYILLÓN: El impacto de los instrumentos comerciales internacionales.- El papel del derecho internacional en América. UNAM, México. Declaraciones de derechos, desde Bill of Rights, las Declaraciones universales de Naciones Unidas, hasta el último aporte regional europeo de naturaleza política incegradora, como es la Carta europea de Derechos fundamentales.

49 Si bien el Estado ha surgido como necesidad de poner punto final al contexto humanamente insoportable en el que se hallaba inmerso el escenario europeo hace ya cinco siglos, los sujetos clásicos de derecho internacional ya no pueblan ni pueden hacerlo la realidad internacional, desde la exclusividad. Organizaciones internacionales, supranacionales y los mismos individuos van ganando terreno a un Estado, que, independientemente de sus dimensiones (USA o Luxemburgo), requiere de un replanteamiento integral para situarse en el tiempo y en el espacio en el que se encuentra inmerso.

so Vid. diferencias constitucionales de los Estados miembros. Vid. C. GrewE, Aa.Vv. "Les conflits de formes entre Droit communauraire et Droits nationaux en matière de droits fondamentaux " (dir. S. Leclerc, J.F. Akandji-Kombé and M.J. Redor), Bruylant, Brussels, 1999.

51 Sobre la concepción de los derechos humanos como universales, hay, sin embargo, docrrina que cuestiona esa universalidad, en el sentido de que es el acervo occidental, el que únicamente ha sido tenido en cuenta a la hora de establecer las grandes Cartas que recogen dichos derechos. Vid en ese sentido fuera del discurso jurídico, KYMLICKA, W: Multicultural Citizenship, Oxford University Press, 1995: HunTINGTON, S.: El cboque de civilizaciones y la reconfiguración del orden mundial, Edit, Paidós, Estado y Sociedad, BarceIona, 2001, los cuales permiten un acercamiento a dicho cuestionamiento, tal y como establecen las consecuencias de la forma de hacer historia (vid. SPENGLeR, O.: La decadencia de Occidente, Editorial Espasa) para la conformación de la cultura socio-jurídica y los valores morales.

52 Vid. Tratado de la Unión, Maastricht, 1992 y reciente Proyecto de Tratado por el que se establece una Consticución para la Unión Europea. 
Por lo que en el caso concreto de la Unión Europea, de forma progresiva e irreversible, se ha venido configurando como una organización supraestatal que independientemente de los Estados, pero basada al mismo tiempo en estos, persigue la configuración de un ente político, apoyado en una fundamentación democrática que pueda legitimar el ejercicio del conjunto de competencias de protección de los derechos y libertades fundamentales, que mediante una estructura institucional pro$\mathrm{pia}^{53}$ garantice la protección de los derechos humanos y los principios democráticos, como valores inalienables.

Por lo que concierne al contexto de la legitimidad democrática, esta supone uno de los retos esenciales para el perfeccionamiento político de la estructura de la Unión, lo que en última instancia implica dar respuesta a la necesidad del individuo de contar con los mecanismos democráticos que le posibiliten sus derechos de relación con el poder público.

Las consecuencias de dicho fenómeno obligan, a su vez, al replanteamiento de la democracia como sistema de gobierno tradicionalmente vinculado a los márgenes estatales para intentar adaptarse a las nuevas exigencias de gobernación por encima de este $\mathrm{e}^{54}$, para evitar que el entendimiento de la democracia se aleje cada vez más de la máxima de "el gobierno del pueblo, por el pueblo y para el pueblo" 55 .

Dentro de este contexto, el demos debe seguir constituyendo la referencia nuclear, en tanto que sujeto activo de este, mediante la existencia de una serie de mecanismos y procedimientos que favorezcan su participación efectiva en el gobierno de la comunidad y que los resultados de las decisiones democráticas se ajusten efectivamente a los intereses y necesidades de los ciudadanos ${ }^{56}$, haciéndose necesaria una estructuración jurídico-política de las relaciones que estos generan, en miras a proteger los criterios propios del Estado ${ }^{57}$ democrático de Derecho, como una prioridad insoslayable, que ordene convenientemente las relaciones entre el nuevo ente resultante, los Estados miembros del sistema y los individuos como protagonistas últimos de dichos procesos.

Si bien la UE representa, a su vez, un modelo de democracia que funciona por encima de los límites del Estado-nación, permanece marcada, sin embargo, por déficit propios de la estructura y del grado de integración, la cual a su vez se encuentra imbuida en el un reto común

\footnotetext{
53 Administración institucional directa e indirecta, dependiente de la admisnitración de los Estados del Derecho comunitario. Vid. Parejo, Ortega Álvarez, Jiménez Campos: (n. 30 ).

54 Vid. Rosenau, J: Turbulence in world politics, 1990, Harverser, NY, Londres, Harvester Whweatsheaf, 1990.

5s Discurso del Presidente Lincoln, de Getrysburg.

56 Vid. VAllespin (n. 4), p.165.

57 Aceptando el paralelismo con la Comunidad democrática de Derecho, vid. Simon, D.: "La Communauré de Droit". Frédéric SuDRE et Henri LABAYle (dir.) En Réalité et perspectives du droit communautaite des droits fondamentaux, Bruylant Bruxelles, 2000.
} 
de "crear infraestructuras capaces de sostener políticas globales internas sin desligarlas de los procesos de legitimación democrática" 58 , por lo que el fenómeno supranacional plantea para la democracia nuevos desafíos y nuevos riesgos.

Dicha estructura funciona con "un sistema decisional parcialmente independiente en referencia a los gobiernos de los Estados miembros, un sistema jurídico parcialmente vinculante para los individuos y los gobiernos (disponiendo de su propio Tribunal de Justicia) la aplicabilidad directa vis a vis de los ciudadanos"59. WeIlen plantea, de forma clara, que "los obstáculos que dificultan el camino de la supranacionalidad normativa, no podrán ser sobrepasados, sino llegando a la supranacionalidad decisional ${ }^{60}$ y comunitaria, y de la democracia"61. Por su parte este autor afirma que "el exceso de supranacionalidad normativa, conlleva paradójicamente a poner en dificultad la aplicación de la supremacía decisional, imbuida por la burocratización del sistema y por otro lado por la ausencia de legitimación formal y substancial" 62 .

Por su parte, factores que no favorecen la comprensión del funcionamiento del sistema por el particular, encuentran su fundamento en la existencia de elementos intergubernamentales, regida por la unanimidad como mecanismo decisorio general, que mantiene la discusión y la toma de decisión de áreas de relevante importancia fuera del potencial acuerdo por mayoría de Estados, lo que repercute tanto en el desarrollo interno de la propia integración como en la percepción del demos y de la Comu-

58 Sin embargo, el modo en que la UE se ha desarrollado hasta el momento, nos encontramos frente a la paradoja. La creación de nuevas instituciones políticas -las autoridades de Bruselas, el Tribunal de Justicia Europeo y el Banco Central Europeo- no significa en modo alguno que la política haya cobrado mayor importancia; la unión monetaria representa el último paso de un proceso en el que a pesar del programa original de Shuman, de De Gasperi y de Adenauer, se puede describir retrospectivamente como "creación intergubernamental de mercados". Ibídem.

59 WeIler, J.H.H, AA.VV.: "Democratie et construction europeenne", Direction Mario Teló, Editions de l'Université de Bruxelles, Érudes Européenes, Ideaux et construction entropéenne, p. 99, Supranational organizations; R. BENHARDT: Encyclopedia of Public International Law, 5, Amsterdam Elsevier, 1983, pP. 262-268; TAYLOR, P.: "Elements of Supranationalism", TAYLOR, P., GROOM, A. J. R.: International organizations, A conceptual approach, London, Pinter 1978, pp. 216-235.

60 También existen otros elementos que son cumplidos de forma parcial por la UE, lá prohibición de opting out y de la retirada unilateral de un Estado miembro sin acuerdo de la organización supranacional y la independencia presupuestaria. Vid. TELó : (n. 28), p. 43.

61 Weiler, J.H.H, AA.Vv. "Democratie et construction européenne" (n. 28), p. 99.

62 Asimismo, el crecimiento del Poder Legislativo del Parlamento y del poder de iniciariva de la comisión refuerza la supranacionalidad o contribuye al menos a formar una especie de veto supranacional. En cuanto a la supranacionalidad decisional, esta es más complicada de realizar ya que cuenta con la integralidad del proceso decisional, la acticud de los Estados para con la UE, la interacción conflictual en el seno del sistema institucional, las dificultades de ejecución, etc. Vid. Teló (n. 28). Vid. WeIler, El sistema comunitario, Il Mulino, 1985. 
nidad Internacional. Dicha dinámica decisoria se combina, a su vez, con la dinámica supranacional basada en la toma de decisión por mayoría, combinación que no deja de presentar un panorama marcadamente particular y específico en el desarrollo de la democracia a dicho nivel ${ }^{63}$.

Estos ámbitos intergubernamentales permanecen reservados, como lo han estado tradicionalmente, a los ámbitos competenciales de los Estados miembros, compatibilizándolos con la realidad de la integración progresiva, constituyendo un límite de primer orden en la evolución de la integración europea ${ }^{64}$.

Desde una perspectiva formal y macrojurídica, "el paradigma de la tensión entre el polo intergubernamental, dominado por el postulado jurídico del principio del Derecho internacional clásico ${ }^{65}$, y el polo comunitario o supranacional ${ }^{66}$, sometido a su vez al principio de integración, muestra una idea clásica de la naturaleza ambigua e híbrida del Derecho comunitario, así como por las dificultades y retos a los que se enfrenta" ${ }^{67}$, reflejan a su vez dos visiones distintas, "una visión unitaria, propuesta por los que preconizaban los Estados Unidos de Europa y una visión comunitaria más atenuada. Esas dos visiones continúan existiendo" ${ }^{68}$, sin perjuicio de que, tal y como recuerda WeILER "los objetivos metapolíticos de la integración, definidos en el preámbulo del Tratado de Roma evocan una Unión cada vez más estrecha entre los pueblos europeos, son la mejor expresión del triunfo comunitario (...). Este triunfo se refleja igualmente en la concepción meticulosa de las instituciones, que vinculan a los Estados miembros participando más estrechamente de lo que se haría en cualquier federación"69.

No aplicándose la regla de la mayoría, que iría en concordancia con una democraticidad en dicho nivel.

64 Como lo constituyen, asimismo, las limitaciones de orden público.

65 Menor democraticidad, por la unanimidad como generalidad.

66 Mayor democraticidad, por decisiones mayoritarias.

67 Jiménez Piernas: (n. 41), pp. 15-48. En relación a J. Martín Pérez de Nanclares: El sistema de competencias de la Comunidad Europea. Germen iusinternacionalista versus vocación federal, Madrid 1997, pp. 14-21. Asimismo, "el paradigma de la tensión entre los conceptos de política y derecho informa también decisivamente todo el proceso de integración gracias a la inestable y rica relación, no siempre pacífica, que se ha entablado entre ellos en la práctica comunitaria"; vid. en este sentido J. Solana: Europa y su futuro, Madrid 2000, Ed. Fundación, conferencia anual Francisco Fernández Ordoñez, pp.42-50; en relación con el informe del 18 de octubre de 1999, preparado por un grupo de personalidades europeas, R. WeIZSACKER, J.L. DehaEne y D. SimON, "Las implicaciones institucionales de la ampliación", en Revista de Derecho comunitario Europeo, número 6, 1999, pp. 595-610, p.597. Vid en este sentido J. Diez-Hochleitner: La posición del Derecho Internacional en el ordenamiento comunitario, Madrid 1998, pp. 59-72. WEILER: (n. 28), p. 99.

69 Ibídem, p. 99. El autor advierte, asimismo, del riesgo de hacer cálculos fríos de los costes y beneficios que se pueden sacar de la integración. Dicha realidad se refleja en una dificultad añadida para la correcta aplicación del Ordenamiento supranacional. Así, todos los Estados miembros tienen, independientemente de la distribución territorial de com- 
Sin embargo, factores adversos como la funcionalidad intergubernamental en la toma de decisiones de reforma de los Tratados, el funcionalismo de las Instituciones europeas, la inexistencia de un pueblo europeo, la falta de elecciones únicas al Parlamento europeo, la particular división de poderes existente, la insuficiente participación del Parlamento en los procesos decisorios, basada durante mucho tiempo en la cooperación como eje de acción, la insuficiente conexión de los parlamentos nacionales con la dinámica europea, el confuso reparto competencial, la falta de transparencia institucional, han supuesto por su parte una serie de obstáculos para el desarrollo democrático del ente creado, los cuales suponen objetivos fundamentales en la evolución de la integración, los cuales van progresivamente viéndose reducidos en la medida que los compromisos estatales van incrementándose con variada intensidad, en beneficio de la integración.

En este sentido la Unión Europea viene desarrollando acciones y políticas concretas de acercamiento del ciudadano al sistema de integración, desde la incorporación en el Tratado de Maastricht de los derechos de ciudadanía, pasando por la codificación de los derechos fundamentales protegidos por la Unión, en la Carta de derechos fundamentales proclamada en Niza e incorporada en el actual Proyecto de Tratado constitucional $^{70}$, como resultado de un proceso convencional de marcado carácter constituyente, en miras a reducir el denunciado déficit democrático ${ }^{71}$ que se imputa a la Unión.

En dicho contexto cabe destacar la incorporación general de conceptos como el de gobernabilidad ${ }^{72}$, la buena administración ${ }^{73}$, en los procesos normativos y administrativos comunitarios, que implica el explícito reconocimiento del ejercicio de los derechos del ciudadano en sus relaciones directas con el aparato público institucional tanto europeo como nacional, a la hora de ver aplicado el Derecho comunitario.

Así, como señala RUBio Llorente, "la tendencia hacia la ampliación del poder comunitario, con la consiguiente limitación estatal, no es coyuntural (...), sino absolutamente estructural. Consecuencia necesaria

petencias, el deber de cooperar, en la medida de sus posibilidades, con el desarrollo y aplicación del Derecho comunitario. En este contexto, ha de existir el principio de independencia de las acciones insticucionales, que refleje la dotación de la que disponen estas para actuar, en unos casos de conformidad con los Estados parte en el acuerdo, y otros con la facultad de imponer lo que el resto de los integrantes ha decidido conforme al proceso de decisiones específicamente establecido al efecto.

70. Vid. página oficial de la Convención, www.europa.eu.int

71 TEló, M.: (n. 28).

72 Vid. HARLOW C., Rawlings: Law and Adminitration, Butterworths, 1997; vid. CraIG, P.: Administrative Law, Sweet and Maxwell, London, 1994. Vid. Gidnens: (n. 4).

73 Ibidem. 
del telos de la integración"74, lo que no implica el hecho de vincular la evolución europea con la necesidad de legitimación democrática, ya que alejarse de dichos parámetros no encontraría (a diferencia de lo que ocurre con la institución de soberanía) ninguna coherencia con la realidad cronológica actual de los Estados que la conforman.

En términos generales, y vinculado al esfuerzo anteriormente mencionado, resultan relevantes para el perfeccionamiento de la democracia al interior de la Unión, las consecuencias generales de sometimiento del comportamiento institucional comunitario a las pautas de buena conducta administrativa, procedentes de la recomendaciones del Defensor del pueblo europeo, los servicios administrativos directos puestos al alcance del ciudadano, las reformas de mejora institucional, así como el incremento del papel del Parlamento europeo en el proceso de creación de normas, el incremento del rol de los parlamentos nacionales en el desarrollo de la integración ${ }^{75}$, el establecimiento en el Tratado de Amsterdam de un procedimiento europeo de sanción política a los Estados cuando incumplan de forma grave y reiterada los compromisos atinentes al artículo $2^{\circ}$ del Tratado, en el que se establecen los valores sobre los que se fundamenta la Unión, principalmente vinculados a la sumisión al Estado democrático de Derecho y a la garantía de protección de los derechos humanos, entre otros ejemplos, todos ellos tendentes a llenar de contenido la prioridad de situar al individuo en el centro del proceso europeo.

\section{B. SOBERANÍA Y PUEBLO EN EL CONTEXTO SUPRANACIONAL EUROPEO}

El fenómeno supranacional en el contexto democrático afecta particularmente al concepto de soberanía, el cual se encuentra en el origen mismo de la concepción del sistema de integración, basado en limitaciones parciales y voluntarias de soberanía, originaria y fundamentalmente delegada mediante cláusula constitucional ${ }^{76}$, en función de la consecución de los fines ${ }^{77}$ preestablecidos vía Tratado por parte de los Estados miembros.

\footnotetext{
7.4 Rubio Llorente, F.: El constitucionalismo de los Estadas integrados de Eurupa, Fundación Ortega y Gasset, Madrid 1996, pp. 15-38. En el mismo sentido, A. L. MILWVARD: The european recue of the Nation-State, Berckley y Los Angeles 1992, p. 343. El Tratado de Maastricht, define como búsqueda de una Unión cada vez más perfecta, de la limitación temporal del proceso y de la técnica urilizada para la atribución de competencias a la Comunidad.

75 Vid. el Protocolo ad buc, incluido en el Proyecto de Tratado constitucional, en el que se pretende dotar de mayor relevancia el rol desempeñado por estos en dicho contexto.

16. Estamos en todo caso ante delegaciones parciales de soberanía en coherencia con la perpetuación de la forma de Estado, como entidad política.

77 Dificultades de diseño de las bases institucionales en el Proyecto de Tratado, las cuales han 1 legado a poner en peligro el consenso convencional, en el que se había estado trabajando. Vid. página oficial de la Convención sobre el futuro de Europa www.europa.eu.int
} 
Si bien dicha delegación de soberanía, tiene un origen constitucionalmente legitimado (porque en ellas se encuentra la base habilitante de la propia integración), sin embargo, se genera a su vez un resultado sui generis que adolece de legitimidad democrática suficiente y que el propio sistema se esfuerza por transformar.

El problema teórico fundamental reside en el hecho de que la doble naturaleza (supranacional e intergubernamental) de la construcción europea afecta a las dos dimensiones de la soberanía ${ }^{78}$, la independencia internacional del Estado y la soberanía popular ${ }^{79}$, distinguiendo desde el punto de vista de los pueblos "entre soberanía del Estado, a nivel de las relaciones interestatales y soberanía del pueblo, es decir, el poder en el seno de la comunidad y el poder entre las comunidades políticas" ${ }^{80}$. La visión más realista, va en la tendencia de concebir un tipo de soberanía compartida entre las organizaciones europeas y los Estados miembros, de transferencia de competencias, unido obligatoriamente a un reforzamiento de la constitucionalización y de procedimientos de control en el seno de la Unión ${ }^{81}$, que se vinculan directamente con la necesidad de incrementar y asegurar su democratización progresiva.

Desde la óptica del contexto global de interdependencia ${ }^{82}$ en sus implicaciones con la soberanía interna, J. HABERMAS mantiene que las decisiones tomadas por los Estados en virtud de su capacidad legítima de autogobernarse en su ámbito socioterritorial, cada vez se corresponden menos con las personas y territorios que pueden ser afectados por ellas, ya que en la sociedad mundial actual se da cada vez con menos frecuencia una correlación entre participantes y afectados ${ }^{83}$.

78 Vid. ibídem, p. 9.

79 Vid. TEló: (n. 28).

80 Ibídem.

81 Vid. Ibidem.

82 Ferrajoli, L.: Derecho y Garantias, Trotta, p. 149. Desde un óptica global se está produciendo, además, una crisis de legitimación en el sistema de soberanías, las cuales se sitúan en planos de desigualdad y de relaciones cada vez más asimétricas entre países ricos y países pobres en una comunidad internacional, que no se podrá sostener a largo plazo, por los propios ordenamientos políticos de los Estados. La solución pasa por el sometimiento a derecho de la Comunidad internacional, como planteó en su día VITORIA, KANT o KelSEN, lo que está poniendo en absoluto cuestionamiento de la soberanía misma, del concepto de Estado como forma política de actuación internacional, además de las insuficiencias que los Estados descentralizados vienen a añadir más candencia a la cuestión. Habermas: (n. 4), p. 95. Vid. Held, D.: "Democracy, the Nation State and the Global System", en Held (comp.): Political Theory Today, Cambridge, 1991, pp. 197-235, aquí pp. 201 y ss. Esta sicuación global como mantiene Habermas (n. 4), p. 143: "ofrece la imagen dinámica de interferencias e interacciones entre los caprichosos procesos políticos que transcurren a nivel nacional, internacional y global. Los sistemas internacionales de negociación, que hacen posibles los acuerdos entre los actores estatales se comunican, por una parte, con los procesos en el interior del Estado de los que dependen los respectivos gobiernos, pero, por otra, los adaptan al marco político: de la organización mundial. De esta forma, por lo menos, surge la perspectiva de una política interior mundial sin go- 
Dicho concepto entra irremediablemente en un proceso dinámico de adaptación, para lo cual será necesario encontrar un equilibrio entre la necesidad de mantener el Estado nacional y la de mejorar, perfeccionar y ampliar la competencia de la organización internacional de estas características, sin afectar las garantías fundamentales de protección constitucional. Como afirma J. Habermas, "el intento de resolver el dilema entre desmontar la democracia del Estado de bienestar o rearmar el Estadonación, nos lleva a buscar unidades políticas mayores y sistemas transnacionales que puedan compensar de las pérdidas funcionales del Estadonación de modo que no sea necesario romper la cadena de legitimación democrática" ${ }^{44}$.

Por su parte G. JÁUREGUI afirma que este proceso puede afectar de forma sustancial a dicho concepto "tanto en su titularidad como en su ejercicio. En lo que respecta a la titularidad, queda fuera de toda duda la consideración del pueblo como sujeto titular de soberanía. Lo contrario implicaría la desaparición de la democracia y el Estado de derecho" 85 .

Sin embargo en el proceso de integración en cuestión, se plantea el problema del entendido como unidad, única y exclusiva, de la que emana o se deriva la titularidad de la soberanía, puesto que se requeriría de la definición del cuerpo político que otorgue legitimación a una pretendida Constitución europea ${ }^{86}$, y hasta el momento no existe la concepción de pueblo europeo, sino la sumatoria de los pueblos de todos y cada uno de los Estados miembros, hecho que de facto desvirtúa el proceso, el cual, sin embargo, tiende progresivamente a una mayor corporización política ${ }^{87}$.

La percepción comunitaria del demos está determinada por una composición plural de todos y cada uno de los demos que componen los de los Estados que de ella forman parte, sin existir un solo y único demos, que actúe como tal, al unísono, en el escenario europeo. Por ahora se cuenta

bierno mundial, presuponiendo que se logre claridad sobre dos problemas. Uno es un problema de principios y el otro de naturaleza empírica. a) ¿Cómo es posible una legitimación democrática de las decisiones más allá de esquema de organización estatal? Y b), ¿ ¿ajo qué condiciones puede transformarse rápidamente la autocomprensión de los actores capaces de acción global, de forma que los Estados y los sistemas supranacionales se entiendan cada vez más como miembros de una comunidad que como tales no tienen más alternativa que una consideración de su recíprocos intereses y una defensa de los intereses generales?".

Habermas, J.: "El valle de lágrimas de la globalización", en Revista Claves de la razón práctica, $\mathrm{N}^{\circ} 109,2001$, p. 8

85 Jáuregui, G.: La Democracia Planetaria. Ediciones Nobel, 2000, p. 127.

86 Vid. material de trabajo y resultados de la Convención para el Futuro de Europa, en www.european.convention,eu.int, especialmente el Proyecto de Tratado para el establecimiento de una Constitución para la Unión Europea.

87 Vid. por ejemplo Carta de Derechos Fundamentales, Catálogo de Garantías de la Unión, que consolida y refuerza la percepción del ciudadano respecto del sometimiento a este de la acción de la Unión, o el capítulo destinado a la Vida democrática del Proyecto de Tratado, que posteriormente se menciona. Vid. en www.europa.eu.int 
más bien con un demos "en construcción" al que una importante parte de la doctrina ${ }^{88}$ considera más ideal que real, a la hora de compararlo con el concepto clásicamente concebido.

Así, del hecho de que las relaciones entre individuo y poder público a nivel de la Unión, hayan estado tradicionalmente marcadas por el distanciamiento, se ha generado un incremento de la falta de identificación de la ciudadanía con el proceso supranacional en curso, hecho que supone un riesgo para el proceso abierto de conformación de un demos o pueblo europeo, como núcleo legitimador del sistema.

Por otra parte, dentro de la realidad actual, la Comunidad ya no se identifica exclusivamente con títulos como el de ciudadanía (reconocido a la totalidad de los nacionales de los Estados miembros), sino que está compuesta de forma cada vez más importante por otros individuos, que a su vez ostentan una nacionalidad que no se corresponde con la de las de la Unión, y que están demandando una concepción mucho más abierta de lo que son los puros conceptos de nacionalidad, ciudadanía, Estado y derechos subjetivos tradicionalmente reconocidos, a su vez en concordancia con el sentido ontológico de la idea de la "integración".

Por su parte, se impone un reconocimiento efectivo de mayor número de derechos fundamentales ${ }^{89}$, que no tengan en cuenta la pertenencia a un grupo, nación o Estado, puesto que el carácter mismo de los derechos fundamentales conlleva la necesidad de "integración", necesidad que se ve claramente plasmada en el componente multinacional, multiétni$\mathrm{CO}^{90}$ y intercultural que se incorpora irreversiblemente a la sociedad europea, no siendo ya posible identificar con la misma claridad ${ }^{91}$ ni facilidad los elementos de Estado, pueblo, nación y cultura.

Así, cada vez resulta más difícil la atribución diferenciada del reconocimiento de ciertos derechos, como los derechos vinculados a la ciudadanía (contemplados en el Tratado ${ }^{92}$ ), los cuales, en base a la nacionalidad comunitaria de los Estados de la Unión, el ciudadano se hace beneficiario de la exigencia de una serie de derechos que le son atribuidos específica y exclusivamente, sin que puedan llevar aparejados situaciones de injusticia social ${ }^{93}$.

\footnotetext{
s. Vid. enfoque general de la obra de WEILER, J., entre otros, como claro ejemplo de dicha cuestión.

89 Vid. Carta de derechos fundamentales, cit.

yo Vid. CAzor, K.: ponencia inédita sobre Multiculturalismo y orden global, Seminario sobre Globalización de la Universidad Austral de Chile, septiembre de 2003. En vías de publicación.

91 Vid. autores clásicos, Rosseau, J., Social contract, Harmondsworth, 1968, entre otros.

92 Vid. Capítulo de Derechos de Ciudadanía en el Tratado, y Capítulo destinado al efecto en la Carta de Derechos fundamenrales.

93 Como situaciones de inmigrantes residentes ante la Administración, etc.
} 
A la situación multipolar que se produce en la Unión ante la cuestión de la ciudadanía (nacionales de todos los Estados de la Unión), se acrecienta la generada por el factor inmigratorio, en clara tendencia de aumento, por lo que algunos derechos de ciudadanía, como el derecho de buena administración ${ }^{94}$, recientemente reconocido como derecho fundamental en el Ordenamiento comunitario ${ }^{95}$ (mediante la proclamación solemne de la Carta de Derechos Fundamentales de la Unión Europea, y posterior inclusión en el Proyecto de Tratado constitucional de la Unión, todavía en proceso de negociación), han visto extendido su reconocimiento, superando los márgenes restrictivos del beneficio de la ciudadanía, y beneficiando a la totalidad de las personas ${ }^{96}$, sin distinción de la plenitud de efectos ${ }^{97}$ (no solamente a los ciudadanos comunitarios) ${ }^{98}$, lo que pone de relevancia un esfuerzo por acercar al individuo, independientemente de su nacionalidad, a las exigencias democráticas cotidianas a las que debe someterse la Administración (local, estatal o comunitaria), a la hora de relacionarse con el individuo, parte de esa sociedad.

\section{PROYeCto CONSTITUCiONAL de La Unión Europea y proceso DE DEMOCRATIZACIÓN}

El sistema de integración europeo presencia actualmente un momento esencial de su construcción política, protagonizado por el proceso de constitucionalización concretado recientemente en los resultados de la Convención sobre el Futuro de Europa, que como órgano de carácter cuasi constituyente ${ }^{99}$, ha sido constituido para llevar a cabo, lo más democrática-

91 Artículo 41 de la Carta: Toda persana tiene derecho a que las instituciones. organismos y agencias de la Unión traten sus asuntos imparcial y eqnitativamente y dentro de un plazo razonable. Este derecho incluye en particular: el derecho de toda persona a ser oida antes de que se tome en contra suya una medida individual que le afecte desfavorablemente. el derecho de toda persona a acceder al expediente que le afecte, dentro del respeto de los intereses legítimos de la confidencialidad y del secreto profesional y comercial, la obligación que incumbe a la Administración de motivar sus decisiones. Toda persona tiene derecho a la reparación por la Unión de los daños causados por sus instituciones o sus agentes en el ejercicio de sus funciones, de confornidad con los principios gencrales comunes a los Derecbos de los Estados miembros. Toda persona podrá dirigirse a las instituciones de la Unión en una de las lenguas de la Constitución y deberá recibir una contestación en esa misma lengua. Vid. artículo 41 de la Carta de Derechos Fundamentales, promulgada e incorporada en el Proyecto actual de Tratado constitucional. Vid. Garcia de Enterría, "La democracia y el lugar de la ley", REDA, 1996.

Una vez ratificado el futuro Tratado, basado en el reciente Proyecto de Tratado por el que se instituye una Consritución para la Unión Europea, en el que se incorpora en la segunda parte del mismo, la Carta de Derechos Fundamentales como catálogo nuclear de dichos derechos.

98 A pesar de estar inserto en el capítulo consagrado a los derechos de ciudadanía, con las consecuentes restricciones generales que estos admiten, respecto de los cuales, el artículo 41 resulta una excepción, con numerosas consecuencias prácticas. Vid. atribuciones del órgano, www.europa.eu.int 
mente posible ${ }^{100}$, la tarea de diseñar el Proyecto de Tratado por el que se pretende instituir una Constitución para la Unión Europea ${ }^{101}$, el cual se encuentra en estos momentos en periodo abierto de negociación, tras las diferencias confirmadas en el Consejo Europeo ${ }^{102}$, en el que no se consiguió llegar a un acuerdo sobre ciertos aspectos ${ }^{103}$, decisivos pero ajenos, sin embargo, al consenso respecto de los valores políticos, Estado de Derecho, Democracia y respeto a los Derechos Humanos, temáticas que interesan a este artículo, y que se mantienen inmutables ante la perspectiva de futuro de la Unión, por lo que es posible afirmar que la preocupación permanente de la Unión por consolidarse como una Comunidad supranacional democrática de Derecho, encuentra un reflejo explícito en el contenido del mencionado Proyecto de Tratado ${ }^{104}$.

Al hacer referencia al concepto de Constitución en dicho contexto (Proyecto de Tratado por el que se instituye una Constitución para la Unión Europea), caben una serie de debates que, sin embargo, por una cuestión de extensión, no serán desarrollados en este contexto, que si permite, no obstante, alguna breve observación.

Identificar al proceso de constitucionalización europeo como un proceso constituyente, implica la necesidad de referirse a este proceso desde una perspectiva amplia de comprensión de las particularidades propias del mismo, lo que no excluye el debate, puesto que desde las posturas más ortodoxas del constitucionalismo, a las más flexibles, se plantea tanto formal como materialmente ${ }^{105}$.

100 Vid. composición, forma de trabajo, transparencia, publicidad, participación, que se mencionan posteriormente en este artículo, como vid. www.europa.eu.int, los documentos del procedimiento de trabajo de la Convención.

101 Vid. documentaçión disponible de elaboración y documento final publicados en la página oficial de la Unión Europea, www.europa.eu.int

102 Vid. publicación oficial de la Convención de 18 de julio de 2003.

103 Relativos fundamentalmente al reparto de poder en el establecimiento del sistema decisorio.

104 Vid. www.europa.eu.int, material disponible sobre la Convención. A propósito de la obstaculización gubernamental ante la aprobación de dicho Proyecto, el cambio de gobierno producido recientemente en España, es susceptible de constituir un factor decisivo en el avance del proceso constitucional abierto, tras la posibilidad que se abre ante un cambio de posición en la política exterior española, que rompa la posición mantenida en el escenario internacional por el gobierno saliente. Vid. EL MUNDO, Victoria del PSOE y retirada de tropas. La 'Vieja Europa' da la bienvenida a Zapatero ante la inquietud de Estados Unidos y Reino Unido, 16 de marzo de 2004. Vid. LE MONDE, 16 de marzo de 2004 . L'axe BlairAznar-Bush s'est brisé le 11 mars, Londres et Washington perdent un allié stratégique. Vid. El Mundo, de 16 de marzo de 2004. Editoriales de los Principales Diarios. La prensa internacional destaca que la victoria del PSOE hará que España se vuelque hacia la UE. Personalmente pienso que dicho elemento repercute directamente en la evolución de la integración, la cual se verá probablemente favorecida por dicho cambio.

105 WeILER, J.H.H. 1999: The Constitution of Europe: "Do the New Clothes Have an Emperor?" and other essays on European integration. Cambridge: Cambridge University Press, del mismo autor. WeIler, J.H.H. 2000: Federalism and Constitutionalism: Europe's Sonderweg, Harvard Jean Monnet Working Paper 10/00, o Vid. Ortega Álvarez, L., La Constitución de Europa, ob. cit. 
Como mantiene G. JÁuREGUI, desde una perspectiva general del proceso "una eventual aprobación de una Constitución europea nos sitúa ante una doble alternativa. 0 bien se sigue manteniendo la tesis clásica de una sola soberanía entendida en su triple sentido de poder supremo, originario e independiente, o bien optamos por la idea de que es posible una soberanía compartida. Si optamos por la primera alternativa, todavía nos queda por resolver el problema de si tal soberanía debe corresponder a la UE, o a los Estados nacionales o, en palabras de RUBIO LLORENTE, si al final termina prevaleciendo la lógica de la integración o la lógica de la soberanía" ${ }^{106}$, quedando siempre la vía de en medio como se puede extraer del proceso constitucional europeo actual, en base a optar por una soberanía compartida ${ }^{107}$, regulada por el principio de subsidiariedad ${ }^{108}$, "que permita un reparto no solo de competencias sino también de soberanía entre los diversos entes o instituciones. Un nuevo modelo, capaz de unir los elementos positivos de los modelos confederal y federal, en el que sea posible limitar el monopolio de los diferentes Estados, tanto a nivel interno como a nivel internacional o, en nuestro caso, europeo, como sujetos de derecho internacional ${ }^{109}$, sin que esto signifique necesariamente acabar con el Estado"110.

Esta cohabitación de soberanía, parte de aceptar la premisa de que esta es suprema, pero en un sentido relativo, es decir, solo respecto al ámbito de competencias que le atribuye la regla que la creó y limitada jurídicamente por las reglas que la constituyen en tal autoridad jurídica (...); no resultando necesariamente única e indivisible ${ }^{111}$, implicando el paso de una soberanía excluyente a una soberanía incluyente, en la que la cooperación no impide sino que despliega la soberanía de los particulares, en la que los agentes estatal-nacionales ganan espacios de configu-

106 Vid. JÁuregui, G.: (n. 85), p. 127.

107 Vid. El concepto de soberanía tiene un carácter relativo, no absoluto, y por tanto es mensurable y susceptible de gradación. Vid. al respecto F. J. BASTIDA, 1999, pP. 381 ss. 22 , citado por el autor, "partiendo de la base de que resulta inevitable una Constitución europea y de que esa nueva soberanía europea no va a producir una extinción de la soberanía de los diversos Estados, sino una superposición de soberanías, entonces se plantea la cuestión de cuál va a ser la soberanía residual de los Estados y cuáles pueden ser los elementos de conflicto entre ambas soberanías". JÁUREGUI, G. (n. 85), p. 127.

108 Vid. Protocolo sobre Subsidiariedad y Proporcionalidad del Proyecto de Tratado constitucional, el cual viene a influir en la conveniencia sobre el ejercicio de acción competencial, en base a los criterios de necesidad y de mayor eficiencia. Vid. ARMIN VON BOGDANDY, El orden competencial vertical de la UE, ponencia en el Colegio de Eméritos de Madrid, 2001.

109 HetD, D. 1995, p. 235. Democracy and the Global Order, Polity Press, Cambridge, 1995). Vid. JÁuregui, G. (n. 85) p. 128.

110 Vid. JÁuregui, G. (n. 85), p. 127. Vid. Documentos de desarrollo de la Convención sobre el debate federalista, CONV. 528/03, cit. en página oficial de la Convención, cit.

111 Vid. ibídem, p. 128. 
ración política en la medida en que consiguen incrementar su protagonismo gracias a la cooperación transnacional ${ }^{112}$.

Conviene tener en cuenta la necesidad de asegurar clara y contundentemente las garantías constitucionales nacionales, ante el declive de la concepción tradicional del Estado entendido como un ente soberano, nacional, en miras a cohabitar con un poder institucional, diferente, supranacionalmente integrado, puesto que en caso contrario, provocaría una pérdida de la primacía y de la entidad primordial que hasta ahora tenía la Constitución, para pasar a situar los instrumentos comunitarios supranacionales por encima de la misma ${ }^{113}$.

No poca discusión ha sido vertida a este respecto ${ }^{114}$ y de una forma o de otra la primacía del Derecho comunitario sobre los derechos nacionales cohabita dentro de los límites preestablecidos con la protección constitucional e internacional (CEDH) de los derechos fundamentales a la cabeza.

Por otra parte, cabe preguntarse, sin embargo, si resulta imprescindible que las constituciones presupongan la existencia de Estados y si puede haber constituciones sin Estados, como la que se proyecta en la Unión Europea ${ }^{115}$, pudiendo entenderse el constitucionalismo más allá de los Estados ${ }^{116}$, en orden a dar cabida a otros modelos y

112 Vid. U. Beck, Qué es la globalización. Barcelona, Paidós. 1998, p. 186. Vid. JÁuregui, G. (n. 85), p. 128

113 Vid. ibídem, p.127. Vid. Alonso Garcia, R., en AA.Vv. Derechos fundamentales y Comunidades europeas, Edit. Civitas. Vid. Alonso GARcía, R., "The General Provisions of The Charter of Fundamental Rights of the European Union", Jean Monet Working Paper 4/02. Vid. para un estudio detallado del proceso constitucional y la existencia de los límites en Derecho comunitario sobre derechos fundamentales, vid. un trabajo reciente al respecto de la misma autora de este artículo, Tesis inédita de la Academia europea de Derecho público sobre las Perspectiva en torno a la Carta de derechos fundamentales, junio de 2003, en fase de publicación, disponible en mfgchile@ hotmail.com, vid. JAUREGU1, G. (n. 85), p. 126

154 Vid. Garcia de Enterrfa, E. "El Proyecto de Constitución europea", en REDC, 45, 1995. Rubio Llorente: "Mostrar los derechos sin destruir la Unión", Revista Española de Derecho Constitucional, Año $22 \mathrm{~N}^{\circ}$ 64, 2002, vid. GosalBo BONO, Ricardo: "Reflexiones en torno al futuro de la protección de los derechos humanos en el marco del derecho Comunitario y del Derecho de la Unión: insuficiencias y soluciones..." Revista de Derecho Comznitario Europeo, Centro de Estudios Constitucionales, 1997. Vid. Rodríguez IGLesias, Gil Carlos y Valle GÁlvez, Alejandro: "El Derecho Comunitario y las relaciones entre el Tribunal de Justicia de las Comunidades Europeas, el Tribunal Europeo de Derechos Humanos y los Tribunales Constitucionales Nacionales, Centros de Estudios Políticos y Constitucionales, año 1997. Vid. MuÑoz MACHADO, S.: El Estado, el derecho interno y la Comunidad Europea. Ed. Civitas, Madrid, 1986, entre otros.

115 Vid. F. de Carreras Serra: "Por una Constitución europea", en REP, 90, 1995. Vid. CARREAU, D. " Droit communautaire et droits nationaux: concurrence ou primauté? La contribution de l'arrêt Simmenthal?", Rev Europe, 1978. Canor, I.: "Primus inter pares. Who a the ultimate guardian of fundamental rights in Europe?", 12000, 25, ELRev, Feb.

116 Vid. Himsworth, C. M G., "In a State no Longer: The end of Constitutionalism?", en Public Law, 1996. Vid. JÁuregui, G. (n. 85), p. 129. 
formas políticas, en todo caso limitadas por el imperio de los valores no negociables del sometimiento a Derecho, basado en la Democracia como modelo político y en la protección y salvaguardia de los derechos humanos ${ }^{117}$, como premisas inalienables de cualquier estructura política que haya de constituirse.

Sin embargo, cabe añadir que si bien el proceso de constitucionalización vivido en el momento actual, supone un avance incuestionable tanto por el proceso mismo en sí, basado en el mecanismo convencional, que por primera vez es utilizado para proceder a la reforma de los Tratados paralelamente al mecanismo clásico de reforma de la Conferencia intergubernamental, como por el contenido mismo y las repercusiones de dicho concepto en sí, el hecho de hablar de Constitución europea, en el estado actual de evolución, por muy avanzado que se considere, puede inducir a una concepción errónea de los cambios que se están sucediendo, puesto que si bien suponen una profundización incuestionable del proyecto en sí, constituye solamente una fase, aunque de especial importancia, en la progresiva gestación constitucional comunitaria.

Personalmente, y de acuerdo con las posiciones mantenidas por autores como R. Alonso García Y L. ORTEga Álvarez ${ }^{118}$, no parece conveniente referirse a dicho Tratado como la Constitución europea, ya que aun cuando supone el resultado de un proceso avanzado de constitucionalización, no es asimilable, sin grandes reservas al concepto de Constitución.

Puede entenderse, más bien, que en el momento actual se pretenden sentar las bases de una potencial futura Constitución, que en mi opinión no vendría en ningún caso determinada mediante la ratificación del Tratado en proyecto, puesto que no se establece todavía el marco normativo fundamental de una federación de Estados, que posibilitaría una Constitución común, a pesar de la voluntad de algunos (especialmente de Francia y de Alemania) para que la pretensión política de federalización fuese incluida en el mismo.

Ello no obsta para que tanto el proceso en sí, como los resultados obtenidos en el mencionado Proyecto, impliquen un avance incuestionable en el proceso político-constitucional de la Unión, incrementando la legitimación democrática, como es posible inferir del análisis del Proyecto mencionado, sobre el cual se presenta una breve síntesis de los elementos más relevantes al caso.

\footnotetext{
117 BradLEY, AA.VV.: "Reflections on thee Human Rights Role of The European Parliament, both in Alston (Ed.)", The EU and Hwman Rights, OUP, 1999.

118 Vid. La Constitución europea, Lección inaugural del curso académico 2003, Publicación de la Universidad de Castilla La Mancha, octubre de 2003.
} 


\section{C.1. Convención, como mecanismo de legitimación democrática}

Son múltiples y variados los enfoques que desde el parámetro democrático podrían analizarse en el proceso de integración europeo. Si bien en el desarrollo del proceso constitucional actualmente en curso, conviene poner de relevancia el rol jugado por la Convención sobre el futuro de Europa, como órgano constituido ad boc, el cual ha sido decisivo para establecer el diseño del futuro Tratado constitucional y refleja, a su vez, Ia importancia que la Unión otorga a las garantías democráticas ${ }^{119}$, por lo que por distintas razones dicho Proyecto constitucional constituye un paso esencial (que no definitivo) en el camino abierto al fortalecimiento de la legitimación democrática en la Unión Europea.

Comenzando por el órgano en cuestión, la Convención sobre el futuro de Europa ${ }^{120}$ (en adelante Convención) fue convocada durante la reunión celebrada en diciembre en Laeken ${ }^{121}$, clausurándose recientemen$t^{122}$, con el objetivo de responder a las cuestiones estructurales pendientes de reforma en el seno de la Unión ${ }^{123}$, lo que se presenta como prio-

119 ERik O. ERIKSEn, John E. Fossum y Agustín J. Menendez: "On constitution making and democratic legitimacy", introduction note on session it http://www.arena.uio.no/events/ conference2002/papers. html

120 Es la segunda Convención de la Unî́n Europea que ha sido creada según el modelo trazado por la anterior, constituida específicamente para la redacción de la Carta de Derechos Fundamentales de la Unión Europea. Es la primera vez que se tratan conjuntamente y en tal grado de profundidad y dimensión, tal variedad de temas institucionales y constitucionales, esenciales del fundamento mismo de la propia Unión. Vid. Cuestiones planteadas en la Declaración para el futuro de la Unión anexada al Tratado de Niza y las planteadas en base al mandato de la Declaración de Laeken. Declaración cit.

122 Aunque queden pendientes algunas cuestiones que serán resueltas con posterioridad a dicha fecha. Vid. Appel pour un référendum dans tous les pays en juin 2004 LE MONDE | 14.06.03 | 13h13 Quelque 450 millions d'Européens issus de 25 pays seront-ils appelés à ratifier par référendum la Constitution européenne, le dimanche 13 juin 2004, jour des élections européennes? C'est l'appel lancé par l'eurodéputé Alain Lamassoure, qui a reçu l'appui de 38 conventionnels sur 105 et de 48 membres suppléants. La Convention propose une Constitution à 450 millions d'Européens, LE MONDE | 14.06.03 | 13h13 "Un résultat imparfait mais inespéré": Valéry Giscard d'Estaing a conclu en ces termes, vendredi 13 juin, les travaux de la Convention pour l'avenir de l'Europe qui venait d'adopter son projet de Constitution européenne. Après quinze mois de débats, la Convention a pu aboutir: son texte sera soumis dès la semaine prochaine aux chefs d'Etat et de gouvernement européens. Ils auront jusqu'à la fin de l'année pour l'adopter, et ne devraient pas en modifier les équilibres. Il devra être ensuite ratifié, par voie de référendum ou par les parlements de chacun des vingt-cinq pays-membres de l'UE. Les principales innovations du projet de Constitution européenne, LE MONDE. FR | 13.06.03 | Les innovations portent aussi bien sur le fonctionnement des institutions européennes que sur les procédures de vote ou sur l'exercice de la démocratie par les citoyens.

123 Principalmente las temáticas de relevancia para el órgano en cuestión, que han sido objeto de Grupos de trabajo específicos referentes a subsidiariedad, naturaleza jurídica de la Carta de derechos fundamentales y adhesión al CEDH, personalidad jurídica, parlamentos nacionales, competencias, gobernanza económica, acción exterior, defensa, simplificación 
ridad general a la hora de sentar las bases para el futuro del sistema de integración europeo. Dichos propósitos han tenido como pretensión unificar y reformar materialmente de forma parcial el contenido del Derecho comunitario originario ${ }^{124}$, estructurando en un único Tratado, los ya existentes, en función de los objetivos establecidos ${ }^{125}$.

Dicho órgano fue creado para servir de base fundamental al debate para la toma de decisión que mediante Conferencia Intergubernamental $(\mathrm{CIG})^{126}$ constituida al efecto, sobre el modo en que la Unión Europea va a enfrentar los retos actuales y futuros, tome ante el mismo. Entre dichos elementos se incluye el debate sobre la conveniencia del mantenimiento de la CIG para reformas posteriores de los Tratados ${ }^{127}$, mecanismo de cuestionada democraticidad.

A pesar de los esfuerzos realizados en este sentido en dicho seno, se ha de contar con la limitante del carácter mixto de la Unión, marcado por la impronta intergubernamental, que se pone de manifiesto a la hora de abordar los procesos decisorios de reforma de los Tratados, que si bien están siendo dotados de una mayor legitimidad democrática (como pone de manifiesto el mecanismo propio de la Convención), sigue manteniéndose en manos de los Jefes de Estado y de Gobierno de los Estados miembros la definitiva decisión al respecto ${ }^{128}$.

Por lo que concierne al proceso de revisión de los Tratados existentes, las Conferencias Intergubernamentales (CIG) se encuentran en el centro del debate sobre el déficit democrático de la Unión, debido a la importancia que estas presentan para la legitimación de los cambios, que genera esencialmente una separación entre el ente y el ciudadano, en base al proceso intergubernamental de toma de decisiones y la voluntad ciudadana al respecto.

Dichas Conferencias han tenido tradicionalmente la función de preservar los Tratados existentes (voluntades escritas de los Estados), modi-

y libertad, seguridad y justicia, así coma en las contribuciones de los propios miembros de la misma y las procedentes del foro de la sociedad civil.

124 Derecho convencional bajo forma de Tratados.

125 Vid. un recorrido por el proceso constitucional reciente. Vid. de la aucora de este artículo, Perspectivas en torno a la Carta de derechos fundamentales. Tesis inédita de la Academia europea de Derecho público. Disponible en mfgchile@hotmail.com, en proceso de publicación.

126 http://european-convention.eu.int

127 El actual Proyecto de Tratado que instituye la Constitución, en el artículo 6.2 de la parte IV, destinada a sus Disposiciones generales y finales, regula su función bajo ciertas condiciones, su función en el procedimiento de reforma del mismo. Contextualizándose en el proceso de integración europeo, este ha ido tomando forma en función del diseño de los Tratados precedentes en estas dos últimas décadas y de sus cláusulas de revisión. Acta Única Europea, Tratado de Maastricht, Tratado de Amsterdam y Tratado de Niza.

128 Vid. www.european.convention.eu.int, vid. Proyecto de Tratado constitucional, CONV. 725/03 de junio de 2003. 
ficándolos sin deteriorar el acquis o acervo comunitario y las fuentes últimas de su revisión ${ }^{129}$. Sin embargo, además de adolecer de criterios de control democrático, decisiones políticas, sin posterior control, dicho procedimiento ha ido perdiendo efectividad principalmente por varias razones, entre otras, la relativa a la dificultad y falta de condiciones de espacios para las negociaciones, por no ser adecuados y por generar tanto en los Estados, como al ciudadano, la sensación al final de que están perdiendo influencia política en el proceso y relación con el mismo respectivamente.

Por otra parte, las posiciones de gobierno rígidas ${ }^{130}$ y la falta de participación institucional ${ }^{131}$ dificultan enormemente las $\cos ^{132}{ }^{132}$, ya que aunque "las instituciones son formalmente parte del proceso, (...) no

129 LODGE, J.. "Intergovernmental Conferences and European Integration: Negotiating the Amsterdam Treaty", in International Negotiations, $\mathrm{N}^{0} 3,1998$, p. 347. "Three types of issue were identified: a) those that could be kept out of the final discussions and for which agreement could be obtained before the European Council in Nice (Court of Justice and Court of First Instance, composition of Institutions other than the Commission); b) pivotal issues (qualified majority, reinforced co-operation) for which rhe Group of Representatives had a mandate to go as far as it could in order to arrive at significant agreements before Nice; and c) questions relating to the balance of power (weighting of votes, composition of the Commission), where there would be only a technical examination of the options on the table and the final decision would be left to the Heads of State or Government in Nice". Vid. YaTAGanAS: "The Treaty of Nice: The Sharing of Power and the Institutional Balance in the European Union - A Continental Persepcrive", in European Law Journal, Vol 7, N ${ }^{\circ} 3,2001$, pp.242-291.Vid. HofFMAnN, Lars: "The Convention on the Future of Europe -Thoughts on the Convention Model", Jean Monnet Warking Paper 11/(02.

130 Presidency Conclusions, Nice European Council Meeting, 7, 8 and 9 December 2000, paragraph II, Press Release: Brussels (8/12/2000) N 400/1/00; Presidency Conclusion, Helsinki European Council, 10) and 11 December 1999, Press Release: Brussels (11/12/ 1999) N*: 00300/1/99; Presidency Conclusion, Cologne European Council Meeting, 3 and 4 June 1999, paragraph IV, CFSP Presidency Statement: Cologne (4/6/1999) - Press: () $\mathrm{N}^{\circ} 150 / 99$.

131 En las que por ejemplo la Comisión juega básicamente un rol tẹ́cnico administrativo, excluyéndola de las actuales negociaciones de reforma de los Tratados, pudiendo solo intentar influenciar proponiendo sus propias sugerencias y soluciones, sin tener ningún estatus ni repercusión en las decisiones intergubernamentales. Por lo que se refiere al Parlamento su papel todavía es menor, puesto que solo mantiene la posición de observador. Tiene reuniones informativas entre las delegaciones de la CIG y el Presidente del Parlamento, pero el impacto actual en las negociaciones ha sido mínimo. Aunque produce informes y opiniones, no recibe la misma atención que las proposiciones de la Comisión. Vid. a estos efectos Presidency Conclusions, Nice European Council Meeting, 7, 8 and 9 December 2000, paragraph II, Press Release: Brussels (8/12/2000) $N^{\circ} 400 / 1 / 00$; Presidency Conclusion, Helsinki European Council, 10 and 11 December 1999, Press Release: Brussels (11/12/1999) $N^{\circ} 00300 / 1 / 99$; Presidency Conclusion, Cologne European Council Meeting, 3 and 4 June 1999, paragraph IV, CFSP Presidency Statement: Cologne (4/6) 1999) - Press: $0 \mathrm{~N}^{\prime \prime}$ 150/99. Christiansen T. and Jørgensen K.E., Negotiating Treaty Reform in the European Union: Ob. cit. Lars HoFFmanN "The Convention on the Future of Europe -Thoughts on the Convention Model", ob. cit.

132 Vid, del mismo autor, QMV for taxation was completely taboo for the British government. Ob, cit. 
ejercen ningún poder oficial" 133 . Por ello Hoffmann mantiene que "el modelo de las CIG parece haber llegado al final en lo que a grandes políticas se refiere", además de la dificultad que aproxima la ampliación y la incapacidad institucional para hacer frente a los cambios de gran envergadura ${ }^{134}$

Debido al hecho de que el modelo de CIG (tal y como se conoce en 1996 y en el 2000) no basta para proveer de soluciones efectivas a los cambios constitucionales que enfrenta la Unión, los jefes de Estado y de Gobierno decidieron, en Niza, convocar otra CIG para el 2004, y se aprovechó la ocasión de Laeken ${ }^{135}$, en 2001, para introducir la convención que llevaría a cabo los trabajos preparatorios para la próxima $\mathrm{CIG}^{136}$, como órgano previo de preparación y profundización de las cuestiones que serán después debatidas en la Conferencia y en la que se establecieron los temas claves para ser trabajados de acuerdo a una metodología, lo más transparente y democrática posible ${ }^{137}$, teniendo especial cuidado en crear un órgano que no llegara, por otra parte, a desbordar con sus propuestas el statu quo ${ }^{138}$.

Dicho órgano constituyente surge como respuesta para posibilitar los compromisos $^{139}$ a los que no se llegaron con el método mencionado ${ }^{140}$, con lo que habría logrado el éxito de satisfacer a los tres grupos distintos de intereses: sus propios miembros, la sociedad civil y a la CIG (2004) ${ }^{141}$.

Actualmente se encuentra abierto el periodo de negociación tras las dificultades que ha sufrido la Unión recientemente en este proceso para

\footnotetext{
133 Ibídem.

134 Introductory Speech by President VALERY GISCARD D'ESTAING to the Convention on the Future of Europe, cit. Lars HOFFMANN "The Convention on the Future of Europe Thoughts on the Convention Model", ob. cit. Vid. CON: 79703, cir,

135 Declaración de Laeken, cit.

136 Órgano establecido ad hoc, con precedente en la elaboración de la Carta de Derechos fundamentals de la Unión Europea. Declatation on the future of the Union, $\mathrm{N}^{\circ} 3$ and 4, Official Journal of the European Community, C 80/85, 10.03.2001.

137 Vid. HOFFMANN (n. 134).

138 Vid. Ibídem.

139 Sin embargo, para constatar quejas, vid. Mercredi 28 mai, à Arhènes, le président de la Commission, Romano Prodi, s'en est violemment pris au projet de M. Giscard d'Estaing et de son présidium. Ha hablado de d'un texte qui ne réussit pas à proposer des solutions, qui menace de paralyser l'Europe", a-t-il dit, accusant le texte du présidium de "ne pas résoudre Les problèmes tréés par -le traité de-Nice".Vid. Madrid, aidée par Londres, organise le blocage de la Convention européenne. LE MONDE | 31.05.03 | 13h14 Trois semaines avant la fin des travaux, les divisions entre les Etats menacent l'avenir de l'Europe commune. La France et les autres pays fondateurs vont prendre une nouvelle initiative.

140 A pesar de que cada gobierno participante en la CIG 2004 tendrá derecho a veto, hay que decir que el veto de las proposiciones trabajadas y acordadas por la Convención, perjudica el desarrollo si no se plantean soluciones alternativas, aceptables por todos los representantes de los Estados, lo que dificulta enormemente el compromiso. Dejando de lado aquí, las expresiones del TJCE a la hora de valorar los Tratados como Constitución para la Unión.

141 HoffmanN (n. 134).
} 
valorar finalmente por parte de los Estados, si el Proyecto de Tratado constitucional nacido de la Convención (cuasi constituyente), con o sin modificaciones para llegar a un posible consenso, es, en su generalidad, el adecuado para establecer las bases de un proyecto de Tratado constitucional, cada vez más cercano a una eventual Constitución para la Unión Europea $^{142}$.

Sin embargo, a pesar de la precaución mantenida, a la hora de enfocar el proceso, hay que destacar la importancia democrática de los beneficios del modelo de la Convención, destacando la combinación del control y transparencia ${ }^{143}$, la pluralidad de la composición, con mayor independencia de las implicaciones políticas ${ }^{144}$, facilitando compromisos efectivos ${ }^{145}$ y favoreciendo finalmente la consolidación de esta, como un instrumento necesario para el desarrollo equilibrado de los cambios estructurales de la Unión.

Generalmente ha sesionado públicamente ante la sociedad civil, academia, prensa, contrariamente a como a la forma de actuar propia de la CIG, que debido a "la carencia de control individual, apertura y transparencia en el proceso de negociación, adolece del mismo déficit democrático que caracteriza el orden institucional de la Unión ${ }^{146}$, carencias que son remediadas en gran parte por el modelo complementario de la Convención, la cual, por su parte, publica sus documentos, aglutinando la representación de diversas instituciones y está más cerca del ciudadano, como lo demuestra el foro, el cual otorga a dicha sociedad civil la oportunidad de contribuir a la discusión sobre el futuro de Europa ${ }^{147}$.

Asimismo, la gran mayoría de los miembros de la Convención ha sido democráticamente elegida, puesto que en su mayor parte son miembros de los parlamentos o gobiernos nacionales ${ }^{148}$, mientras que la mayor parte de los participantes en la CIG, a parte de los Ministros y Jefes de Gobierno/Estado, no están directa y democráticamente legitimados"149, como intento de reducir el déficit democrático, por el cual la UE es objeto de crítica. Constituye por tanto un éxito democrático el hecho de

Vid. CONV. 797/03, cit.

Vid. Composición, en capítulos anteriores.

Ver http://www.fedtrust.co.uk/conferences.htm; LE MONDE, Choisir une Europe sous influence américaine ou une Europe indépendante; Interview with Michel Barnier, 23.05.2002, Giscard d'Estaing, V. Le Monde, La derniere chance de l'Europe unie, 23. 07. 2002; FT Interview with Valery Giscard d'Estaing, 07. 10. 2002.

Ibídem.

Ibídem.

Vid. HoffmanN (n. 134).

The only exceptions would be the two Commission representatives, who have been nominated to their position rather than elected, and a few government representatives who are not formally part of their national governments; like the German government representative Peter Glotz who is a university professor in Switzerland.

Ibídem. 
reunir a las principales partes interesadas en dicho proceso ${ }^{150}$ (aunque con distintas capacidades de influencia), incluidos los países candidatos a la adhesión, los cuales participarán plenamente en las deliberaciones ${ }^{151}$, si bien no podrán impedir el consenso que pudiera alcanzarse entre los Estados miembros ${ }^{152}$. A pesar de que, como mantiene LARS HOFFMANN, un periodo de 12 meses de dedicación a la misma, "es un periodo corto de tiempo para producir un documento que potencialmente dé respuestas a todas las cuestiones planteadas por la Declaración de Laeken ${ }^{153}$, y fundamentalmente para concebir un documento que quiere ser la primera Constitución europea" 154 .

Se ha estimado en muchos sentidos que la Convención puede ser considerada como una mezcla ideal de políticas, derecho y participación ciudadana, que puede ser la llave de futuros cambios constitucionales en la UE, reconsiderando su papel, mejorando su funcionamiento y encontrando nuevos cauces de progreso y de democracia ${ }^{155}$.

Muy importante a efectos de acercamiento de la sociedad civil ha sido la previsión de establecimiento por la Declaración de Laeken, de la creación de un forum de organizaciones de la sociedad civil, como se hizo mención anteriormente, en el que se han podido verter sus contribuciones al debate, siendo oídas, consultadas (interlocutores sociales, medios económicos, organizaciones no gubernamentales, círculos académicos, etc.), registradas y publicadas, las cuales representan la pluralidad de

150 Sobre la Composición: El Consejo Europeo nombró a D. Valéry Giscard D'estaing Presidente de la Convención y a D. Giuliano Amato y D. Jean-Luc Dehaene Vicepresidentes. La Convención reúne a las principales partes interesadas en el debate sobre el futuro de la Unión. Además de su Presidente y de sus dos Vicepresidentes, la Convención consta de: 15 representantes de los jefes de Estado o de gobierno de los Estados miembros (1 por Estado miembro), 13 representantes de los jefes de Estado o de gobierno de los países candidatos a la adhesión (1 por país candidato), 30 representantes de los parlamentos nacionales de los Estados miembros ( 2 por Estado miembro), 26 representantes de los parlamentos nacionales de los Estados miembros ( 2 por país candidato), 16 representantes miembros del Parlamento Europeo, 2 representantes de la Comisión Europea.Cada uno de los miembros titulares de la Convención tiene un suplente. El Comité Económico y Social (tres representantes), el Comité de las Regiones (seis representantes), los interlocutores sociales (tres representantes) y el Defensor del Pueblo Europeo asisten en calidad de observadores.

151 Declaración de Laeken.

152 Vid, ibídem.

153 Finalmente derivó en una selección de principalmente las temáticas de relevancia, que han sido objeto de Grupos de trabajo específicos en torno a: subsidiariedad, naturaleza jurídica de la Carta de derechos fundamentales y adhesión al CEDH, personalidad jurídica, parlamentos nacionales, competencias, gobernanza económica, acción exterior, defensa, simplificación y libertad, seguridad y justicia, así como en las contribuciones de los propios miembros de la misma y las procedentes del foro de la sociedad civil.

154 Vid. HOFFMANN (n. 134), aunque finalmente han sido 15 meses de trabajo.

155 Vid. Información general sobre la Convención. www.european-convention.eu.int Vid. Artículos 33-37 sobre la vida democrática de la UE. En el título Vid. CONV 650 de 2 de abril. 
voces que quieren hacerse escuchar a la hora de diseñar el documento constitucional ${ }^{156}$.

A su vez, las organizaciones que participan en el Foro reciben regularmente información acerca de los trabajos de la Convención, labor desempeñada por los Grupos de trabajo que han pretendido dar solución a los problemas constitucionales de la Unión, sobre una serie de materias ${ }^{157}$, los cuales fueron creados en junio de 2002, compuestos por miembros de la Convención ${ }^{158}$, reuniéndose cada uno de los cuales para abordar cuestiones sobre las que debe formular dictámenes pormenorizados ${ }^{159}$, incorporando las contribuciones de dicho foro, se incorporan al debate ${ }^{160}$.

En base a que la idea global de la Convención ha sido reconsiderar el papel de la Unión Europea, mejorar su funcionamiento, encontrar nuevos cauces de progreso y de democracia, entre ellos dejar despejado el camino para clarificar el rol de la Unión en el mundo ${ }^{161}$, las expectativas de los ciudadanos o la ampliación de la Unión Europea, ámbitos de vital

156 Entre ellas destacan las contribuciones del EPC, de temática general o las de la AFEM, EWLA, si bien desde la perspectiva de los intereses fundamentalmente sectoriales de la mujer y la farnilia, han contribuído con un trabajo exhaustivo y permanente durante el transcurso de la Convención.

157 Subsidiariedad, Carta de derechos fundamentales, personalidad jurídica, parlamentos nacionales, competencias, gobernanza económica, acción exterior, defensa, simplificación y libertad, seguridad y justicia.

iss Con el fin de profundizar en sus reflexiones, la Convención ha decidido constituir grupos de trabajos sobre temas concretos cuyo tratamiento detallado en las sesiones plenarias sería dificultoso. Según avancen los trabajos de la Convención, se podrán crear nuevos grupos de trabajo.

159 Independientemente de los Grupos de trabajo presentados, los cuales concluyeron sus trabajos con la presentación del Informe Final ad hoc, la Convención ha recurrido al establecimiento del Grupo de expertos constituido por los Servicios jurídicos de las tres instituciones, para proceder al análisis de ciertas materias específicas del Tratado sobre las que se ha requerido un análisis especial, para que mediante los informes requeridos al caso, presenten, asimismo, propuestas de solución, conforme a los objetivos previstos. Vid. ibídem. Como el Informe sobre la parte II del Tratado constitucional, Vid. http:// european-convention,eu.int Dichas materias han sido determinadas en base a la Declaración sobre el futuro de la Unión Europea realizada por el Consejo Europeo en Niza y a la Declaración de Laeken. Sobre la repartición de competencias entre la Unión y los Estados conforme al principio de subsidiariedad, vid. DECLARACIÓN DE LAEKEN. Vid. SChWARZe JuRgen: "Perspectivas constitucionales de la Unión Europea ante la próxima CIG de 2004. Comunicación 7 noviembre de 2001", Sppech, Colegio de Eméritos, Madrid.

160 Dichas organizaciones pueden ser oídas o consultadas sobre asuntos concretos, en la forma que determina el Praesidium. Como lo fue la sesión plenaria de la Convención Europea de los días 24 y 25 de junio de 2002 que se dedicó a la sociedad civil. Diversas asociaciones y organizaciones tuvieron la oportunidad de expresar y presentar en dicha sesión sus puntos de vista ante los miembros de la Convención.Vid. http://europeanconvention.eu.int

101 Otorgándole definitiva y formalmente la personalidad jurídica internacional vía Tratado, de la que la Unión, a pesar de su reconocimiento de facto, en la escena internacional carecía hasta ahora, personalidad que quedaba repartida en la propia de las Comunidades de origen. 
importancia en estos momentos, materias que serán objeto de debate ${ }^{162}$ en la próxima Conferencia Intergubernamental.

Por ello se ha planteado con éxito, al menos en el presente proyecto, si es que este modelo de Convención no debiera reformar el modelo de reforma de los Tracados establecido por la $\mathrm{CIG}^{163}$, tal y como ha sido formalizado por el Proyecto de Tratado constitucional ${ }^{164}$, puesto que a pesar de las críticas debidas a la generación de mayor burocratización y mayor complicación institucional al complejo panorama actual ${ }^{165}$, elementos como la pluralidad de composición, los espacios de debate, la flexibilidad, la facilidad de crear compromisos o la apertura, justifican su existencia y a pesar de que el modelo de la Convención ${ }^{166}$, si bien, a pesar de no tener capacidad para acabar con los problemas que emanan de la propia CIG, sí viene a facilitar el proceso y a hacerlo más legítimo, preparando "el terreno para una nueva estructura institucional más cercana al ciudadano y levantarla sobre unas bases más democráricas y legítimas" 167.

Sin embargo, a pesar de los beneficios del método de la Convención sobre el de la CIG, la opción de sustitución de la CIG, por la Convención, no puede ser prevista por el momento, puesto que la transferencia de poderes y competencias para este tipo de acciones no ha sido otorgada a otro órgano diferente de esta ${ }^{168}$, por lo que por ahora no le está permitido reemplazar completamente a la CIG en sus funciones como órgano principal de modificación de Tratados ${ }^{169}$, aunque la Convención en sí tiene vocación para "ser institucionalizada para preparar la CIG2170, tal y como recoge el Proyecto de Tratado constitucional, que recoge reconociendo con su formalización en su articulado, la importancia de este mecanismo como un exponente esencial para el desarrollo y evolución del sistema.

162 Vid. De Schutter. O: "Les questions à résoudre Ob. cit. - La protection des droits fondamentaux, un enjeu de la Conventionpour l'avenir de l'Europe", enhttp:// europa.eu.int/comm/justice_home/unit/charte/fr/questions.html.

163 Vid. Disposiciones generales, CONV. 725/03, cit.

164 Vid. CONV. 820/03 de 20 de junio de 2003, Página oficial de la Convención cit.

165 Ibídem.

166 Vid. igualmente el epígrafe dedicado a la Convención que dio a luz la Carca de derechos fundamentales, en el que se detallan elementos comunes a la actual convención sobre el futuro de Europa.

167 HOFFMANN (n. 134).

168 A la cual por otra parte tampoco le han sido transferidos.

169 Por ahora consiste en un órgano complementario a la CIG, para la toma de decisiones más adecuada.

170 Crossick, Stanley: "As the pace of the debate accelerates, provides a snapshot of the emerging consensus in the Convention", The European Policy Centre, February 2003 en http:l/www theepc.be. Por ello, la Constitución europea, tal y como se entiende en las circunstancias acruales, podría valorarse en el sentido de un paso efectivo para la consolidación del constitucionalismo europeo, en consecuencia con la progresiva difuminación 
Por su parte JÁuregui habla de la necesaria tendencia al establecimiento de "un constitucionalismo ${ }^{171}$ regulador de un ordenamiento jurídico complejo en el que sea posible la convivencia de órdenes jurídicos diversos no sustentada, necesariamente, en relaciones jerárquicas de supra o subordinación, sino en criterios de compartición, coordinación y subsidiariedad"172.

Si bien la máxima expresión de la soberanía de un país se expresa en su Constitución, la cual adquiere rango de ley o Carta Fundamental que es fuente de todo el ordenamiento jurídico y prevalece sobre él, sin embargo el derecho constitucional y la justicia constitucional no pueden permanecer estáticos ni indiferentes ante el nuevo orden internacional, por lo que si en las legislaciones internas no se encuentran los mecanismos para la solución expedita de los problemas que plantean las nuevas relaciones internacionales, es preciso buscar las soluciones en mecanismos alternativos voluntariamente aceptados por los Estados y que paulatinamente se introduzcan los cambios necesarios en las legislaciones nacionales, que permitan superar y prevenir las crisis en este sentido.

Por su parte ZAGREBELSKY mantiene que "los términos a los que hay que asociar la ductibilidad constitucional a la que se hace referencia, son la coexistencia y el compromiso. La visión de la política que está implícita, no es la relación de exclusión e imposición por la fuerza (relación amigo-enemigo bobbesiano y scbmittiano), sino la inclusiva de la integración a través de la red de valores y procedimientos comunicativos, que es además la única visión no catastrófica de la política posible de nuestro tiempo"173.

En todo caso, la congruencia del proceso constitucional europeo pasa por la sumisión a los cánones constitucionales preestablecidos y necesarios para dar contenido al concepto mismo de Constitución, abocado, sin embargo, como las principales categorías jurídico-políticas, a adaptarse de la mejor forma posible a los cambios que implican la pertenencia a la escena internacional actual.

entre el derecho interno y el derecho internacional, en miras a ir estableciendo bases sólidas para un nuevo orden mundial o, en palabras de FERRAJOLI, un constitucionalismo mundial.

FERRAJoli: "La conquista de América y la doctrina de la soberanía exterior de los Estados", en Bergal.l1, Roberto, y Resta, Eligio: Soberania: Un principio que se derrumba, Paidós, Barcelona, 1996, p. 175.

173 Zagrebelsky, G.: "El derecho ductil. Ley, derechos y justicia", Edit. Trotta, ob. cit. p. 14; en relación a RUFFILl., R.: "Crisis dello stato moderno: ideologie e istituzione", Il Mulino, Bologna, 1984, p. 213. 


\section{C.2. Referencias a los aportes específicos del Proyecto de Tratado constitucional de la Unión Europea relacionados con el proceso democrático}

El Proyecto de Tratado constitucional constituye el resultado de una serie de esfuerzos realizados y mantenidos para la mejora de la estructura general de la Unión y en particular de su sentido político.

Dicha pretensión está plasmada en distintas partes del Proyecto ${ }^{174} \mathrm{y}$ constituye una materia transversal de toda su estructura jurídica. A renglón seguido, se presentan las menciones de mayor relevancia para dicho análisis, ligadas al concepto de sociedad democrática, vinculado a su vez con el respeto a los derechos fundamentales y a la conveniente representación política, tanto a nivel nacional como europeo, a la participación ciudadana en sus relaciones con el poder público comunitario, como aspectos más relevantes vinculados con la temática que se aborda.

Comenzando por el Preámbulo y encabezando el Tratado constitucional, aparece la primera mención dedicada a la sociedad democrática como valuarte de la Unión.

Presentan especial relevancia la mención directa que se hace a la Democracia, en el contexto de la definición y los Objetivos de la Unión, en la parte I, en su Título I, artículo $1^{0175}$ sobre la creación de la misma, en la que pretende dejar constancia de la legitimidad de la futura Constitución, por medio de la voluntad ciudadana y de los Estados miembros.

Si bien dicha redacción pudiera resultar forzada si se analiza la participación directa de los ciudadanos en el proceso de integración, lo cierto es que sí existen cauces que otorgan una mayor legitimación, como lo han puesto de relevancia la formación y desempeño del órgano constituyente y las posteriores consultas populares que para su aceptación, se llevasen a cabo en su momento, para valorar la aceptación de dicho Proyecto por los ciudadanos de los Estados miembros, a los cuales tiene por destinatarios finales.

El artículo $2^{\circ 176}$ sobre los Valores de la Unión, establece los fundamentos sobre los que se basa la Unión, entre los cuales, la democracia aparece como principal, junto al valor de la dignidad humana, la libertad, la igualdad, el Estado de Derecho y el respeto a los derechos humanos.

174 CONV. 820/03, de 20 de junio de 2003, Proyecto de Tratado por el que se instituye una Constitución para Europa.

175. "La presente Constitución, que nace de la voluntad de los ciudadanos y de los Estados de Europa (...),

176 "La Unión se fundamenta en los valores de respeto a la dignidad humana, libertad, democracia, igualdad, Estado de Derecho y respeto a los derechos bumanos. Estos valores son comunes a los Estados miembros en una sociedad caracterizada por el pluralismo, la tolerancia, la justicia, la solidaridad y la no discriminación". 
En el artículo $3^{0177}$ se establecen los objetivos de la Unión, entre los cuales destacan, como metas relacionadas con la democracia, la de combatir la marginación social y la discriminación, de fomentar la justicia y la protección sociales, la igualdad entre mujeres y hombres, la solidaridad entre las generaciones, la protección de los derechos del niño, el fomento de la cohesión económica, social y territorial y la solidaridad entre los Estados miembros, el respeto de su diversidad cultural y lingüística y la preservación y el desarrollo del patrimonio cultural europeo.

En lo que concierne al contexto de las relaciones exteriores de la Unión, destaca la voluntad de afirmar y promover los valores anteriormente mencionados junto con sus intereses, contribuyendo a la paz, la seguridad y al desarrollo, dejando constancia del compromiso que la Unión tiene en sus relaciones con terceros ${ }^{178}$.

En lo referente a la ciudadanía de la Unión, esta beneficia una serie de derechos, los cuales están contenidos en la Carta de derechos fundamentales, recogida íntegramente en la segunda parte del Tratado, así como el artículo $8^{\circ}$ del Proyecto de Tratado en el Título II $^{179}$ de la primera parte del Tratado sobre Derechos fundamentales y ciudadanía europea, hace referencia a la misma.

Entre estos derechos destaca el de sufragio activo y pasivo en las elecciones al Parlamento Europeo y en las elecciones municipales del

177 Arrículo 1-3: Objetivos de la Unión:

1. La finalidad de la Unión es promover la paz, sus valores y el bienestar de sus pueblos.

2. La Unión of recerá a sus ciudadanos un espacio de libertad, seguridad y justicta sin fronteras anteriores y un mercado único en el que la competencia sea libre y no esté falseada.

3. La Unión obrará en pro de una Europa caracterizada por un desarrollo sostenible basado en un crecimiento económico equilibrado, en una economía social de mercado altamente competitiva, tendente al pleno empleo y al progreso social, y en un nivel elevado de protección y mejora de la calidad del medio ambiente. Asimismo, promoverá el progreso científico y técnico.

La Unión combatirá la marginación social y la discriminación y fomentará la justicia y la protección sociales, la igualdad entre mujeres y bombres, la solidaridad entre las generaciones y la protección de los derechos del niño.

La Unión fomentará la cohesión económica, social y territorial y la solidaridad entre los Estados miembros. La Unión respetará la riqueza de su diversidad cultural y lingüistica y velará por la preservación $y$ el desarrollo del patrimonio cultural europeo.

4. En sus relaciones con el resto del mundo, la Unión afirmará y promoverá sus valores e intereses. Contribuirá a la paz, la seguridad, el desarrollo sostenible del planeta. la solidaridad y el respeto mutuo entre los pueblos, el comercio libre y equitativo, la erradicación de la pobreza y la protección de los derechos bumanos, especialmente los derechos del niño, la estricta observancia y el desarrallo del Derecho internacional, y en particular respeto a los principios de la Carta de las Naciones Unidas. 5. Estos objetivos se perseguirán por los medios apropiados, con arreglo a las competencias atribuidas a la Unión en la presente Constitución.

178 Un buen ejemplo de la preocupación por el desarrollo democrático de terceros países, lo constituye el Acuerdo de asociación, recientemente acordado entre la Unión Europea y Chile, cuarta generación plus, en el cual queda manifestado dicho compromiso a la hora de establecer como uno de los ejes de acción fundamental del mismo, el diálogo político. Vid. Acuerdo de asociación citado, en www.europa.eu.int

179 Vid. contenido concreto en el Proyecto de Tratado anteriormente mencionado disponible en la página oficial de la Unión Europea. 
Estado miembro en el que residan, en las mismas condiciones que los nacionales de dicho Estado.

Los requisitos democráticos se encuentran asimismo en el Título IX en su artículo $57^{\circ}$ al tratar las condiciones de pertenencia a la Unión, entre los que figura el compromiso de respetar y promover en común los valores del artículo $1^{\circ}$ y $2^{\circ}$ mencionados. Por otra parte se establecen las medidas de sanción al Estado o Estados que incurran de forma grave y persistente en el incumplimiento de los mismos en el artículo $58^{\circ}$.

Entre las materias de especial atención en el Tratado, la vida democrática de la Unión tiene consagrada el Título VI, en el que se establecen el Principio de igualdad democrática ${ }^{180}$, en el que se asegura el trato igualitario a los ciudadanos por las instituciones ${ }^{181}$.

Seguidamente se consagra el Principio de democracia representativa ${ }^{182}$, fundamento de funcionamiento de la Unión, como asimismo el Principio de democracia participativa ${ }^{183}$, que alude a los cauces necesarios para recibir institucionalmente la opinión ciudadana.

Destacan entre ellos, el establecimiento de una nueva vía, en base al reconocimiento de la iniciativa legislativa popular. Asimismo se enfatiza la importancia de la transparencia en el funcionamiento general de las instituciones, así como en el rol de los partidos políticos a la hora de

180 Artículo 1-44: Principio de igualdad democrática

La Unión respetará en todas sus actividades el principio de la igualdad de sus ciudadanos. Estos gozarán por igual de la atención de las instituciones de la Unión.

181 Vid, igualmente artículo 41 sobre el derecho fundamental a una buena administración, de la Carta de derechos fundamentales, integrada en el Proyecto de Tratado, cit.

182 Artículo 1-45: Principio de democracia representativa:

1. El funcionamiento de la Unión se basa en el principio de la democracia representativa.

2. Los ciudadanos estarán directamente representados en la Unión a través del Parlamento Europeo. Los Estados miembros estarán representados en el Consejo Europeo y en el Consejo de Ministros por sus gobiernos, que serán responsables ante los parlamentos nacionales elegidos por sus ciudadanos. 3. Todo ciudadano tiene derecho a participar en la vida democrática de la Unión. Las decisiones serán tomadas de la forma más abierta y próxima a los ciudadanos de la Unión.

4. Los partidos políticos de dimensión europea contribuyen a la formación política de la conciencia europea y a expresar la voluntad de los ciudadanos de la Unión.

183 Articulo 1-46: Principio de democracia participativa

1. Las instituciones de la Unión darán a los ciudadanos y a las asociaciones representativas, por los cauces apropiados, la posibilidad de expresar e intercambiar públicamente sus opiniones sobre todos los ámbitos de acción de la Unión.

2. Las instituciones de la Unión mantendrán un diálogo abierto, transparente y regular con las asociaciones representativas y la sociedad civil.

3. Al objeto de garantizar la coherencia y la transparencia de las acciones de la Unión, la Comisión mantendrá amplias consultas con las partes interesadas.

4. Un número significativo de ciudadanos $-q u e$ no será inferior a un millón-procedentes de un número significativo de Estados miembros podrá pedir a la Comisión que presente una propuesta adecuada cuando los ciudadanos estimen que se requiere un acto jurídico de la Unión a efectos de la aplicación de la Constitución. Mediante ley europea se determinarán las disposiciones relativas a las condiciones y procedimientos específicos por los que se regirá esta iniciativa ciudadana. 
representar a estos en el Parlamento, como resultado de la prioridad tomada por la Unión, la cual últimamente ha basado sus acciones en el objetivo general de definir y acercar claramente al pueblo del que una eventual Constitución europea futura reciba su legitimación y establecer "en qué medida va a resultar posible la compatibilidad entre ese pueblo titular de la soberanía europea con la del pueblo titular de la soberanía en la que se asientan las respectivas constituciones estatal-nacionales"184. En el mismo contexto se contempla el papel del Defensor de Pueblo ${ }^{185}$, el cual fiscalizará los casos de mala administración ${ }^{186}$. También la tan valorada transparencia institucional ${ }^{187}$ aparece consagrada especialmente en relación con la buena gobernanza, con la publicidad y apertura de la acción institucional, así como en referencia al derecho ciudadano al acce-

JÁUREGUI (n. 85).

Artículo 1-48: El Defensor Europeo del Pueblo

El Parlamento Europeo nombrará un Defensor Europeo del Pueblo, que recíbirá, investigará y dará cuenta de las reclamaciones relativas a casos de mala administración en las instituciones, organismos o agencias de la Unión. El Defensor Europeo del Pueblo ejercerá sus funciones con total independencia.

Vid. artículo 41 de la Carta, resultado de las labores principalmente del Defensor del Pueblo Europeo, en el que se reconoce el derecho fundamental a una Buena Administración, con el desglose de derechos fundamentales que allí se contienen vinculados principalmente con el procedimiento administrativo comunitario, como asimismo el artículo de la Carta dedicado particularmente a sus funciones.

\section{Artículo 1-49: Transparencia de los trabajos de las instituciones de la Unión}

1. A fin de fomentar una buena gobernanza y de garantizar la participación de la sociedad civil, las instituciones, organismos y agencias de la Unión actuarán con el mayor respeto posible al principio de apertura.

2. Las sesiones del Parlamento Europeo serán públicas, así como las del Consejo en las que este examine o adopte una propuesta legislativa.

3. Todo ciudadano de la Unión y toda persona física o jurídica que resida o tenga su domicilio social en un Estado miembro tendrá derecho a acceder a los documentos de las instituciones, organismos y agencias de la Unión, en las condiciones establecidas en la Parte III, cualquiera que sea la forma en que estén elaborados dichos documentos.

4. La ley europea fijará los principios generales y los limites que regularán, por motivos de interés público o privado, el ejercicio del derechso a acceder a dichos documentos.

5. Cada institución, organismo o agencia mencionado en el apartado 3 establecerá en su reglamento interno las disposiciones específicas sobre el acceso a sus documentos, de conformidad con la ley europea prevista en el apartado 4.

Artículo -50: Protección de datos personales

1. Toda persona tiene derecbo a la protección de los datos personales que la conciernan.

2. La ley europea establecerá las normas sobre protección de las personas físicas en lo que respecta al tratamiento de datos personales por las instituciones, organismos y agencias de la Unión, así como por los Estados miembros en el ejercicio de las actividades comprendidas en el ámbito de aplicación del Derecho de la Unión, y sobre la libre circulación de estos datos. El respeto de dichas normas estará sometido al control de una autoridad independiente.

Articulo 1-51: Estatuto de las iglesias y de las organizaciones no confesionales

1. La Unión respetará y no prejuzgará el estatuto reconocido, en virtud del Derecho nacional, a las iglesias y las asociaciones o comunidades religiosas en los Estados miembros.

2. La Unión respetará asimismo el estatuto de las organizaciones filosóficas y no confesionales.

3. Reconociendo su identidad y su aportación específica, la Unión mantendrá un diálogo abierto, transparente y regular con dichas iglesias y organizaciones. 
so a la documentación, todos ellos derechos que, junto con los vinculados a la relación entre ciudadanía y poder público comunitario, aparecen incluidos como derechos fundamental a una Buena Administración en el artículo 41 de la Carta $^{188}$, asegurando una serie de pautas de conducta administrativas que aseguren al ciudadano el ejercicio de sus libertades democráticas más cotidianas.

Paralelamente aparecen las referencias al papel de los interlocutores sociales y diálogo social autónomo ${ }^{189}$.

Por lo que atañe al papel fundamental de los Parlamentos naciona$\operatorname{les}^{190}$ en la participación del desarrollo de la Unión, conviene destacar la

188 Toda persona tiene derecho a que las instituciones, organismos y agencias de la Unión traten sus asuntos imparcial y equitativamente $y$ dentro de un plazo razonable. Este derecho incluye en particular: el derecho de toda persona a ser oida antes de que se tome en contra suya una medida individual que le afecte desfavorablemente, el derecho de toda persona a acceder al expediente que le afecte, dentro del respeto de los intereses legitimos de la confidencialidad y del secreto profesional y comercial; la obligación que incumbe a la Administración de motivar sus decisiones. Toda persona tiene derecho a la reparación por la Unión de los daños causados por sus instituciones o sus agentes en el ejercicio de sus funciones, de conformidad con los principios generales comunes a los Derechos de los Estados miembros. Toda persona podrá dirigirse a las instituciones de la Unión en una de las lenguas de la Constitución y deberá recibir una contestación en esa misma lengua.

189 Artículo 1-47: Interlocutores sociales y diálogo social autónomo

La Unión Europea reconocerá y promoverá el papel de los interlocutores sociales a escala de la Unión, teniendo en cuenta la diversidad de los sistemas nacionales; facilitará el diálogo entre ellos, dentro del respeto a su autonomía.

190 RECORDANDO que el modo en que cada parlamento nacional realiza el control de la actuación de su propio gobierno con respecto a las actividades de la Unión atañe a la organización y práctica constitucional propias de cada Estado miembro,

DESEANDO, no obstante, impulsar una mayor participación de los parlamentos nacionales en las actividades de la Unión Europea e incrementar su capacidad para manifestar su opinión sobre las propuestas legislativas $y$ otros asuntos que consideren de especial interés,

HAN CONVENIDO en las disposiciones siguientes, que se incorporarán como anexo a la Constitución:

1. Información a los parlamentos nacionales de los Estados miembros

1. Todos los documentos de consulta de la Comisión (libros blancos y verdes y comunicaciones) serán transmitidos directamente por la Comisión a los parlamentos nacionales de los Estados miembros cuando se publiquen. La Comisión remitirá asimismo a los parlamentos nacionales de los Estados miembros, al mismo tiempo que al Parlamento Europeo y al Consejo de Ministros, el programa legislativo anual, así como cualquier otro instrumento de programación legislativa o de estrategia politica que presente a ambas instituciones.

2. Todas las propuestas legislativas remitidas al Parlamento Europeo y al Consejo de Ministros se remitirán simultáneamente a los parlamentos nacionales de los Estados miembros.

3. Los parlamentos nacionales de los Estados miembros podrán dirigir a los presidentes del Parlamento Europeo, del Consejo de Ministros y de la Comisión un dictamen motivado sobre la conformidad de una propuesta legislativa con el principio de subsidiariedad, con arreglo al procedimiento previsto en el Protocolo sobre la aplicación de los principios de subsidiariedad y proporcionalidad.

4. Entre el momento en que la Comisión transmita al Parlamento Europeo, al Consejo de Ministros y a los parlamentos nacionales de los Estados miembros una propuesta legislativa en las lenguas oficiales de la Unión Europea y la fecha de inclusión de dicha propuesta en el orden del día del Consejo con miras a su adopción o a la adopción de una posición en el marco de un procedimiento legislativo, deberá transcurrir un plazo de seis semanas, salvo excepciones por motivos de urgencia, debiendo mencionarse estos en el acto o la posición del Consejo. A lo largo de esas seis semanas no podrá constatarse ningún acuerdo sobre una propuesta legislativa, salvo en casos urgentes debida- 
importancia concedida a los mismos ${ }^{191}$ en el proceso de constitucionalización, en miras a asegurar su participación activa mediante ciertas medidas al efecto, confirmando y fortaleciendo su rol en el desarrollo general de la actividad de la Unión, como el fomento de la transparencia y la facilitación de información y participación de los parlamentos nacionales en el proceso legislativo, en su rol de control efectivo tanto del rol a desempeñar por sus representantes nacionales, como respecto de la dinámica general del proceso, destinándose, de acuerdo a la importancia presentada por esta materia, un Protocolo específico.

Por lo que concierne a los efectos del sometimiento de la actuación de la Unión, destaca el Protocolo sobre la aplicación de los principios de subsidiariedad y proporcionalidad ${ }^{192}$, aplicables a la totalidad de la acción de la Unión a la hora del ejercicio de competencias.

Unido al contexto democrático, la protección de los derechos fundamentales aparece en el Tratado en una posición principal, de conformidad

mente motivados. Entre la inclusión de una propuesta en el urden del dia del Consejo y la adopizón de una posición deberán transcurrir diez dias.

5. Las órdenes del día y los resultados de las sesiones del Consejo de Ministros, incluidas las actas de las sesiones del Consejo de Ministros en las que este delibere sobre propuestas legislativas, se comunicarán directamente a los parlamentos nacionales de los Estados miembros, al mismo tiempo que a los gobiernos de los Estados miembros.

6. Cuando el Consejo Europeo prevea hacer uso de la disposición del primer párrafo del apartado 4 del artículo 1-24 de la Constitución, informatrá a los parlamentos nacionales antes de tomar cualquier decisión. Cuando el Consejo Europeo prevea hacer uso de la disposición del segundo párrafo del apartado 4 del artículo $1-24$ de la Constitución, informará a los parlamentos nacionales al menos cuatro meses antes de tomar cualquier decisión.

7. El Tribunal de Cuentas remitirá a título informativo su informe anual a los parlamentos nacionales de los Estados miembros, al mismo tiempo que al Parlamento Europeo y al Consejo de Ministros. 8. En el caso de los parlamentos nacionales bicamerales, estas disposiciones se aplicarán a las dos cámaras.

II. Cooperación interparlamentaria

9. El Parlamento Europeo y los parlamentos nacionales definirán conjuntamente el modo de organizar y potenciar de manera eficaz y periódica la cooperación interparlamentaria en el seno de la Unión Europea.

10. La Conferencia de Órganos Especializados en Asuntos Europeos podrá dirigir al Parlamento Europeo, al Consejo de Ministros y a la Comisión cualquier contribución que juzgue conveniente. Dicha Conferencia fomentará además el intercambio de información y de prácticas idóneas entre los parlamentos de los Estados miembros y el Parlamento Europeo y entre sus comisiones especializadas. La Conferencia podrá asimismo organizar conferencias interparlamentarias sobre temas concretos, en particular para debatir temas de política exterior y de seguridad comín asi como de política común de seguridad $y$ de defensa. Las aportaciones de la Conferencia no vincularán en absoluto a los parlamentos nacionales ni prejuzgarán su posición.

191 Sobre este particular, vid, http://european-convention.eu.int Vid. el informe final del Grupo de trabajo ad boc VI. Vid. http://european-convention.eu.int. Vid. Stanley CrosSICK: "As the pace of the debate accelerates, provides a snapshot of the emerging consensus in the Convention". Ob. cit, vid. Peter HaIN "The future of Europe: 'a Union of sovereign member states' " (20/03/03) speech by the secretary of state for Wales, ob. cit. Vid. CONV. 725/03, cit.

192 En el que se establece textualmente que:

DESEANDO asegurar que las decisiones se tomen lo más cerca posible de los ciudadanos de la Unión; 
con lo esencial de su rol, a la hora de valorar la garantía de su ejercicio y aseguramiento efectivo, en su relación directa con las premisas democráticas.

Por su importancia en el proceso constitucional llevado a cabo hasta la fecha y en miras a las perspectivas de crecimiento del sistema de integración hacia futuro, dichas garantías han sido recogidas en el Pro-

DECIDIDAS a establecer las condiciones para la aplicación de los principios de subsidiariedad y proporcionalidad enunciados en el artículo $1-9$ de la Constitución, así como a instaurar un sistema de control de la aplicación de dichos principios por parte de las instituciones, HAN ACORDADO las siguientes disposiciones, que se incorporarán como anexo a la Constitución:

1. Cada institución deberá garantizar de manera permanente el cumplimiento de los principios de subsidiariedad y de proporcionalidad definidos en el artículo 1-9 de la Constitución.

2. Antes de proponer un acto legislativo, la Comisión procederá a amplias consultas. Estas consultas deberán tener en cuenta, cuando proceda, la dimensión regional y local de las acciones consideradas. En casos de urgencia excepcional. la Comisión no procederá a estas ionsultas. Motivará su decisión en su propuesta.

3. La Comisión remitirá todas sus propuestas legislativas, así como sus propuestas modificadas, a los parlamentos nacionales de los Estados miembros al mismo tiempo que al legislador de la Unión. El Parlamento Europeo remitirá sus resoluciones legislativas y el Consejo de Ministros sus posiciones a los parlamentos nacionales de los Estados miembros inmediatamente tras su adopción.

4. La Comisión motivará su propuesta en relación con los principios de subsidiariedad y de proporcionalidad. Toda propuesta legislativa deberia incluir una ficha con pormenores que permitan evaluar el cumplimiento de los principios de subsidiariedad y de proporcionalidad. Esta ficha debería incluir elementos para evaluar el impacto financiero y, cuando se trate de una ley marco, de los efectos en la normativa que ban de desarrollar los Estados miembros, incluida, cuando proceda, la legislación regional. Las razones para concluir que un objetivo de la Unión puede alcanzarse mejor a su nivel deberán justificarse mediante indicadores cualitativos y, cuando sea posible, cuantitativos. La Comisión tendrá debidamente en cuenta la necesidad de que cualquier carga, tanto financiera como administrativa, que recaiga sobre la Unión. los gobiernos nacionales, las autoridades regionales o locales, los agentes económicos o los ciudadanos sea lo más reducida posible y proporcional al objetivo que se desea alcanzar.

5. Todo parlamento nacional de un Estado miembro o toda cámara de un parlamento nacional podrá, en el plazo de seis semanas a partir de la fecha de transmisión de la propuesta legislativa de la Comisión, enviar a los presidentes del Parlamento Europeo, del Consejo de Ministros y de la Comisión un dictamen motivado que exponga las razones por las que se considera que la propuesta no se ajusta al principio de subsidiariedad. Incumbirá a cada parlamento nacional o a cada cámara de un parlamento nacional consultar, cuando proceda, a los parlamentos regionales que posean competencias legislativas.

6. El Parlamento Europeo, el Consejo de Ministros y la Comisión tendrán en cuenta los dictámenes motivados dirigidos por los parlamentos nacionales o cualquiera de las cámaras de un parlamento nacional.

Los parlamentos nacionales de los Estados miembros que cuenten con un sistema parlamentario unicameral dispondrán de dos votos. mientras que cada una de las cámaras en un sistema parlamentario bicameral dispondrá de un voto.

Cuando los dictámenes motivados sobre el incumplimiento del principio de subsidiariedad por parte de la propuesta de la Comisión representen al menos un tercio del total de votos atribuidos a los parlamentos nacionales de los Estados miembros y a las cámaras de los parlamentos nacionales, la Comisión deberá volver a estudiar su propuesta. Este umbral será de al menos una cuarta parte cuando se trate de una propuesta de la Comisión o de una iniciativa de un grupo de Estados miembros presentadas con arreglo al articulo $111-160$ de la Constitución relativo al espacio de libertad, seguridad y justicia.

Tras este nuevo estudio, la Comisión podrá decidir mantener su propuesta, modificarla o retirarla. La Comisión motivará su decisión. 
yecto constitucional en el artículo $7^{0193}$ de la Primera parte del mismo, materia que comparte con en el Título II, con los derechos de ciudadanía europea.

La segunda parte del segundo volumen del Proyecto de Tratado, se destina a la Carta de los derechos fundamentales de la Unión, incluyendo el texto completo con Preámbulo y Disposiciones Generales ${ }^{194}$, tal y como fue solemnemente proclamada ${ }^{195}$, en el contexto de la precedente y primera Convención que la dio existencia originariamente como Declaración política solemne.

\section{C.3. Especial referencia a la Carta de derechos fundamentales como núcleo constitucional europeo}

La proclamación solemne de la Carta de Derechos Fundamentales de la Unión Europea ha constituido un paso esencial en la consolidación y protección de dichos derechos, facilitando el acercamiento de los ciudadanos al conjunto de derechos y libertades fundamentales que protege y persigue la Unión, fortaleciendo la sumisión aplicativa institucional del Derecho comunitario al respeto de los derechos y principios que en ella

7. El Tribunal de Justicia será competente para conocer de los recursos de incumplimiento del principio de subsidiariedad por parte de un acto legislativo, interpuestos de acuerdo con los procedimientos previstos en el artículo 111-266 de la Constitución por los Estados miembros, o transmitidos por estos de conformidad con su ordenamiento jurídico en nombre de su parlamento nacional o de una cámara del mismo.

De conformidad con el mismo artículo de la Constitución, el Comité de las Regiones también podrá interponer recursos respecto de actos legislativos para cuya adopción la Constitución requiera su consulta.

8. La Comisión presentará al Consejo Europeo, al Parlamento Europeo, al Consejo de Ministros $y$ a los parlamentos nacionales de los Estados miembros un informe anual sobre la aplicación del artículo 1-9 de la Constitución. Este informe anual deberá remitirse asimismo al Comité de las Regiones.

193 Traducción hecha del francés del Doc. CONV: 724/03 de 25 de mayo de 2003, todavía no disponible en español. Dicho artículo establece: 1. La Unión reconoce los derechos, las libertades y los principios enunciados en la Carta de derecbos fundamentales que constituye la segunda parte de la presente Constitución. 2. La Unión se esfuerza en adherir el Convenio Europeo de derechos del bombre y de las libertades fundamentales. La adbesión a este Convenio no modifica las competencias de la Unión, tal y como son definidas por la presente Constitución. 3. Los derechos fundamentales tal y como son garantizados por el Convenio europeo de derechos del hombre $y$ libertades fundamentales y tal y como resultan de las tradiciones constitucionales comunes de los Estados miembros, forman parte del derecho la Unión, como Principios generales.

194 Con las modificaciones sugeridas por el Grupo II, vid. Informe final del Grupo II CONV. (OR. en) CONV 354/02 WG II 16 Bruselas, 22 de octubre de 2002 (24.10) así como ciertos ajustes añadidos.

195 Tal y como fue proclamada solemnemente, con algunas modificaciones derivadas del trabajo de la Convención concluida sobre el futuro de Europa. 
se contienen, de acuerdo con los parámetros democráticos y de Estado de Derecho (Comunidad de Derecho ${ }^{196}$ ) en los que se funda la Unión ${ }^{197}$.

Asimismo, se ha transformado en un marco referencial básico, para los órganos de la Unión, fortaleciendo internamente la seguridad jurídica, facilitando la labor del Tribunal de Justicia e impulsando a la Unión a someterse a una Declaración única de derechos fundamentales, aplicabilidad general, como parte del objetivo común de respetar y proteger dichos derechos, aunque también recibió en su momento una serie de críticas, como la referente a la falta de reconocimiento de naturaleza jurídica, las relacionadas con el tratamiento de los derechos sociales o las cuestiones de redacción y de falta de precisión.

La Carta de derechos fundamentales ${ }^{198}$ presenta en forma de catálogo nuclear de la estructura constitucional de la Unión, la totalidad de los derechos fundamentales reconocidos por esta ${ }^{199}$, así como los principios democráticos y de respeto al Estado de Derecho, sobre las cuales se sustenta dicha protección comunitaria, constituyendo el núcleo de protección de dichos derechos para el Ordenamiento jurídico comunitario, como base política del mismo.

196 Vid. Simon, D. " La Communauté de Droit", F. Sudre et H. LABAYle (dir.), en Réalité et perspectives du droit communautaire des droits fondamentaux, BRUYLANT, Bruxelles, 2000.

197 Vid. Artículo $2^{\circ}$ del Título 1 del Proyecto de Tratado constitucional, CONV. 820/03 cit. La Unión se fundamenta en los principios de respeto a dignidad humana, libertad, democracia, Estado de Derecho y respeto a los derecbos bumanos. Estos valores son comunes a una sociedad caracterizada por el pluralismo, la tolerancia, la justicia, la solidaridad, y la no discriminación. Solemnemente proclamada e incorporada al proyecto de Tratado constitucional Vid. BERING LiIsBerg, J.: "Does the EU Charter of Fundamental Rights Threaten the Supremacy of Community Law. Article 53 of the Charter. A Fountain of Law or Just an Inkblot?", Harvard Law School. The Jean Monnet Chair, Paper 010401, points 2 and 4). Vid. BESSELINK, L. "Enfrapped by the Maximum Standard", CMLR 35 1998., BESSELINK, L.: "The member States, the National Constitution and the Scope of the Charter", Maastricht Journal of European and Comperative Law, 2001. J. A. CARRILlo SALCEDO: "Notas sobre el significado político y jurídico de la Carta de derechos fundamentales de la Unión Europea", en Revista de Derecho comunitario europeo. CEPC. Enero 2001; BRAIBANT, G.: La charte des droits fondamentaux de l'Union européenne, Edit. Du Seuil, 2001.; G. DE BurCA: "The drafting of the European Union Charter of Fundamental Rights", 2001, 26, E.L. Rev. 126.

199 Vid, entre la numerosa bibliografía al respecto, ALONSO GARCIA, R.: "The General Provisions of The Charter of Fundamental Rights of the European Union", Jean Monet Working Paper 4/02.; Alonso García, R.: "La Carta de los derechos fundamentales de la Unión Europea", en Gaceta Jurídica de la Unión Europea N ${ }^{\circ} 209$, septiembre-octubre 2000.; AREZZA, L.: Le forme di rilevanza della Carta dei diritti Fondamentali dell'Unione Europea en La Difficile Costituzione europea (dir. U. De Siervo), Il Mulino, Bologna, 2001.; G. DE BURCA: "The drafting of the European Union Charter of Fundamental Rights", 2001, 26, E.L. Rev. 126; Juan Antonio CARRIllo SALCEDO: "Notas sobre el significado político y jurídico de la carta de derechos fundamentales de la Unión Europea", en Revista 
En el Preámbulo de la Carta ${ }^{200}$, se incluye una referencia expresa a la sociedad democrática ${ }^{201}$ así como se incluye en el Preámbulo del Proyecto oficial de Tratado constitucional mencionado 202 .

Paralelamente a las referencias específicas a la materia democrática anteriormente referidas, existen ciertos artículos relacionados que merecen ser tenidos en consideración por la importancia de su contenido como el artículo $2^{\circ}$ de la Primera parte ${ }^{203}$, que trata sobre los valores en los que se fundamenta la Unión; los derechos de ciudadanía del artículo $8^{\circ 204}$; los objetivos de la Unión establecidos en el artículo $3^{\circ}$, así como el artículo $4^{\circ}$ relativo a las libertades fundamentales y a la no discriminación; junto con el artículo $5^{\circ}$ sobre las relaciones de la Unión y los Estados miembros $^{205}$, todas ellas destinadas a cumplir un rol ineludible para la adecua-

de Derecho comunitario europeo, CEPC, Enero 2001; BRAIBANT, G.: La charte des droits fondamentaux de l'Union européenne, Edit. Du Seuil, 2001.; Vlad Constantinesco.: "La Carta Europea de Derechos Fundamentales. Una visión desde Francia", en Anuario de derechos bumanos nueva época, volumen 2, Instituto de Derechos Humanos. Facultad de Derecho Universidad Complutense Madrid, 2001; Difz-PiCazo Jiménez, L. M.: "Glosas a la nueva Carta de Derechos fundamentales de la Unión Europea", en Tribunales de Justicia, 5, 2001.

"La Unión Europea contribuye a la preservación y al fomento de estos valores dentro del respeto de la diversidad de culturas y tradiciones de los pueblos de Europa (...)". Preámbulo de la Carta de los derechos fundamentales de la Unión Europea. C 364/8. Diario Oficial de las Comunidades Europeas.18.12.2000:

Los pueblos de Europa, al crear entre sí una unión cada vez más estrecba, han decidido compartir un porvenir pacifico basado en valores comunes.

Consciente de su patrimonio espiritual y moral, la Unión está fundada sobre los valores indivisibles y universales de la dignidad bumana, la libertad, la igualdad y la solidaridad, y se basa en los principios de la democracia y del Estado de Derecho. (...) La Unión contribuye a la preservación $y$ al fomento de estos valores comunes dentro del respeto de la diversidad de culturas y tradiciones de los pueblos de Europa, así como de la identidad nacional de los Estados miembros y de la organización de sus poderes públicos en el plano nacional, regional y local; trata de fomentar un desarrollo equilibrado y sostenible (...) reforzar la proteción de los derechos fundamentales a tenor de la evolución de la sociedad, del progreso social y de los avances cientificos y tecnológicos. La presente Carta reafirma, respetando las competencias y misiones de la Comunidad y de la Unión. así como el principio de subsidiariedad, los derecbos reconocidos especialmente por las tradiciones constitucionales y las obligaciones internacionales comunes de los Estados miembros, el Tratado de la Unión Europea y los Tratados comunitarios, el Convenio Europeo para la Protección de los Derechos Humanos y de las Libertades Fundamentales, las Cartas Sociales adoptadas por la Comunidad y por el Consejo de Europa, así como por la jurisprudencia del Tribunal de Justicia de las Comunidades Europeas y del Tribunal Europeo de Derechos Humanos. El disfrute de tales derecbos origina responsabilidades y deberes tanto respecto de los demás como de la comunidad humana y de las futuras generaciones (...) En consecuencia, la Unión reconoce los derechos, libertades y principios enunciados a continuación.

CONV. 797/03, cit., de 12 de junio de 2003. Vid. CONV. 820/03, cit. a la hora de que la Europa ahora reunida (...) desea ahondar en el carácter democrático y transparente (...). La Unión se funda sobre los valores de respeto a la dignidad bumana, de libertad. de democracia, de Estado de derecho, así como en el respeto de los derechos humanos. Estos valores son comunes a los Estados miembros en una sociedad caracterizada por el pluratismo. la tolerancia, la justicia, la igualdad, la solidaridad y la no discriminación. Traducido del francés del Doc. CONV: 724/03, cit. Vid. CONV. 724/03, cit.

205 Vid. la redacción de todos ellos, en CONV. 724/03, cit. 
da interpretación de la totalidad de disposiciones que se inscriben en dicho Tratado.

Como límites legítimos de la aplicación del Derecho comunitario, presentan suma importancia el rol desempeñado por la protección constitucional de los Estados miembros de los derechos fundamentales, respecto de la cual aparecen referencias directas, tanto de distintas formas en el texto del Proyecto de Tratado constitucional ${ }^{206}$.

A estos efectos concretos, podrían ser igualmente útiles, por la amplitud interpretativa que añaden, las referencias contenidas en el artículo $2^{\circ 207}$, anteriormente mencionado, el artículo $5^{\circ} .1^{\circ 208}$, sobre el respeto a la identidad y estructuras constitucionales nacionales y el propio mandato constitucional del artículo $3^{\circ} .3$ del mismo anteproyecto ${ }^{209}$.

Sin embargo, de la falta de tratamiento de las tradiciones constitucionales no comunes de los Estados miembros, omitidas en ambas partes del Proyecto de Tratado ${ }^{210}$, plantea un cuestionamiento ${ }^{211}$ relevante respecto del mantenimiento de la diversidad cultural-constitucional de los Estados miembros, invocada por otra parte formal del Tratado.

206 Las referencias directas aparecen en el artículo 7 (en el apartado $1^{\circ}$, de forma general e indirecta cuando se refiere a la Carta y en el apartado $3^{\circ}$ de este mismo artículo), así como en las Disposiciones generales de la Carta, concretamente en la segunda parte del mismo en el artículo 52 (en el apartado $4^{\circ}$, y eventualmente en el apartado $6^{\circ}$ ) y como principalmente en el artículo 53 sobre el nivel de protección.

Artículo 1-7: Derechos fundamentales

1. La Unión reconoce los derechos, libertades y principios enunciados en la Carta de los Derechos Fundamentales que constituye la Parte II de la presente Constitución.

2. La Unión procurará adherirse al Convenio Europeo para la Protección de los Derechos Humanos $y$ de las Libertades Fundamentales. La adbesión a dicho Convenio no afectará a las competencias de la Unión que se definen en la presente Constitución.

3. Los derechos fundamentales que garantiza el Convenio Europeo para la Protección de los Derechos Humanos y de las Libertades Fundamentales y los que son fruto de las tradiciones constitucionales comunes a los Estados miembros forman parte del Derecho de la Unión como principios generales. Vid. CONV. 724/03, cit., CONV. 725/03, cit. y CONV. 797/03, cit.

En el que se establece que "la Unión respetará la identidad nacional de sus Estados miembros, inherente a sus estructuras fundamentales politicas y constitucionales (...) principalmente a (...) mantener el orden püblico".

"La Unión respeta la identidad nacional de los Estados miembros y sus estructuras (...) constitucionales (....)" Vid. CONV. 724/03, cit. Vid. Ante Proyecto de la Presidencia, cit. En el cual, en el título Objetivos de la Unión, se establece que "la Unión constituirá un espacio(...) donde se respete la riqueza de su diversidad cultural". Vid. Ante Proyecto de la presidencia, cit.

210 Vid. artículo 7 y Disposiciones generales de la Carta, CONV. 820/03, cit.

211 Vid. artículo $2^{\circ}$ cit. En el respeto general de la diferencia, pero que, sin embargo, desconoce a la hora de establecer garantías concretas que favorezcan dicha pretensión. Vid. CONV. 724/03, cit. tal y como titula la Constitución en el Título I, sobre Definición y Objetivo. Si bien el final de la frase "como se precisa en la Carta" plantea un límite bastante indefinido al ejercicio de dícho mandato. Vid. artículo 52.6 de la parte II, del CONV. $725 / 03$, en las Disposiciones Generales. Vid. M. Fernández Gutiérrez, en Perspectivas en torno a la Carta de Derechos Fundamentales de la Unión Europea, cit. 
Por lo que concierne al límite que suponen para el ejercicio de la acción comunitaria, los compromisos internacionales en la materia, los acuerdos internacionales ${ }^{212}$, tienen reconocida su importancia de forma general en el Proyecto de Tratado constitucional, aunque fundamentalmente reducida al Convenio europeo de Derechos Humanos y Libertades Fundamentales $(\mathrm{CEDH})^{213}$.

En relación al control externo de la aplicación del Derecho comunitario, el establecimiento de una cláusula habilitante que posibilite en su caso la adhesión ${ }^{214}$ de la Unión (con personalidad jurídica internacional oficialmente recientemente reconocida vía Tratado, una vez en vigor el mismo), supone un paso esencial en el camino hacia un potencial sometimiento vinculante de la Unión a los parámetros internacionales establecidos por dicho Convenio, encabezado por la jurisprudencia del Tribunal Europeo (TEDH) planteando una posibilidad de futuro distinta a la actual, resolviendo al menos el problema técnico-material ${ }^{215}$ existente a estos efectos.

212 Vid. Jacob SöDerman: "European Ombudsman. The Convention, the Charter and the Remedies", EPC Dialogue: The Convention and the Charter of Fundamental Rights. The European Policy Centre, Brussels, 25 February 2003 http://www.euro-ombudsman.eu.int/ speeches/fr, vid. FERNÁNDEZ SOLA, Natividad: "A quelle necessite juridique repond la negociation d'une charte des droits fondamentaux de Union Européenne?", en Revue du Marché Commun et de l'Union Européenne. N. 442, oct-nov. 2000. Vid, CANOR, I.: "Primus inter pares. Who a the ultimate guardian of fundamental rights in Europe?", 12000, 25, ELRev, Feb.

213 Por su parte el artículo 7 del Proyecto de Tratado, omite cualquier tipo de referencia expresa a la generalidad de los convenios internacionales, con excepción del CEDH. Dichos instrumentos se han visto, sin embargo, reconocidos en las Disposiciones generales (En el cual se hace referencia al derecho internacional y a los convenios internacionales de los que la Unión, la Comunidad o todos los Estados son parte, principalmente dejando mención del CEDH) de la Carta (tal y como ha sido incorporada en la segunda parte del Proyecto de Tratado), por lo que, al menos indirectamente, están presentes en el contexto de dicho artículo 7.1, por la presencia que la Carta tiene reconocida en el mismo. Por otra parte, en base a este mismo argumento de presencia indirecta, se constata su presencia en el Preámbulo (En el cual se habla del cumplimiento de las obligaciones internacionales de forma general) y en el artículo 53 de la misma Carta, a la hora de establecer la disposición general sobre el nivel de protección (Cuando establece que "Ninguna disposición de la presente Carta podrá ser interpretada para limitar o restringir los derechos humanos y las libertades fundamentales reconocidas, en su ámbito de protección respectivo por el derecho de la Unión, el derecho internacional y los convenios internacionales de los cuales sea parte la Unión, la Comunidad o todos los Estados miembros y principalmente el Convenio europeo de derechos humanos y libertades fundamentales, así como por las Constituciones de los Estados miembros". Vid. CONV. 725/03, cit.), donde queda visiblemente reflejada la diferencia de la importancia otorgada al CEDH, respecto de la del resto de los convenios internacionales existentes. De este artículo, se echa en falta la importancia del reconocimiento a la jurisprudencia del TEDH. Por otra parte, dicha previsión no parece hacerse extensiva al resto de los convenios potencialmente aplicables al Ordenamiento comunitario.

214 Vid. Dictamen 2/94 del TJCE respecto a la posibilidad de adhesión al CEDH, en que fue denegada tal posibilidad a la Comunidad.

215 Vid art. 5 del CONV 528/03 y posteriormente el art. 7 del anteproyecto, CONV. 724/03. 
Sin olvidar que la diferencia existente entre establecer la cláusula general habilitante ${ }^{216}$ y la decisión de adherir dicho Convenio, decisión que compete tomarla a los Estados miembros en el escenario intergubernamental, supone un elemento importante para la posibilidad del establecimiento a futuro, de un control externo formal e internacional por el $\mathrm{TEDH}^{217}$, sobre el alcance otorgado por el sistema comunitario a las garantías de derechos y libertades fundamentales propias de las tradiciones políticas y constitucionales europeas.

\section{BREVES CONCLUSIONES}

La Unión Europea cada vez más consciente de las implicaciones políticas que suponen los compromisos comunitarios derivados de la integración, asumidos por los Estados miembros en favor de esta, promueve e institucionaliza progresivamente cauces para el acercamiento de la sociedad europea actual a la conformación de un pueblo único europeo, que constituya la base para una integración política profunda, como confirmación de la democracia a un nivel supraestatal.

Sin embargo, el proceso de integración en curso, constituye un proceso marcado por la influencia de una variedad de factores que van repercutiendo en forma, ritmo e intensidad distinta, en la consecución de los objetivos existentes, por lo que resultan esenciales los esfuerzos permanentes y progresivos, en miras a la consolidación de la Unión Europea

216 La Carta Europea de los Derechos Fundamentales, elaborada por una convención ad hoc, se adoptó el 18 de diciembre de 2000. En ella se fijan los valores morales y éticos comunes a todos los Estados de la Unión. Este mismo Grupo ha estado encargado igualmente de dilucidar las cuestiones concernientes a la potencial adhesión al CEDH de la Comunidad/Unión, temática que no será presentada en este trabajo. Vid. http://europeanconvention.eu.int Vid. Informe oral de la Presidencia sobre el estado de avance de la Convención, de 16 de abril de 2003.Vid. Anteproyecto de Tratado constitucional, artículo 5. cit, y enmiendas y reacciones a las enmiendas. La disyuntiva está entre integrarla en la segunda parte del Tratado, o en un Protocolo anexo. Vid. Stanley Crossick "As the pace...", ob. cit. Vid, ibídem. Vid. artículo 5 del anteproyecto del Tratado constitucional (inicial artículo 6, dicho artículo ha cambiado de numeración y pasaría a ser el art. 5, tras la presentación oficial del 04/3/2003, en el que se presentan los primeros cinco títulos, sobre el que se aportan modificaciones. www. european-convention.eu.int Sobre las propuestas de modificación vid: Proyecto de artículos 1 a 16 del Tratado Constitucional (27$28 / 2 / 03$ ), de 6 de febrero de 2003, CONV 528703. Vid. Más las proposiciones de enmienda vertidas sobre las proposiciones de los artículos. Pág. De la convención, vid informe sobre las reacciones: Nota de transmisión; 574/03 de 21 de febrero de 2003, y Nora de transmisión 574/1/03 de 26 de febrero de 2003, para tener constancia de las posiciones por representante y tema, Vid. CONV. 724/03, Conv. $725 / 03$ de 25 y 26 de mayo de 2003. Vid. 797/03, cit.

217 Tras las modificaciones y ajustes necesarios para una posible integración del sistema supranacional en la estructura internacional del CEDH. Vid. Informe del comisario A. VITORINO de la Convención al respecto. 
como una Comunidad democrática y de Derecho, respecto de la cual, el Proyecto de Tratado para instituir una Constitución resultante y su posterior aprobación, representan un paso de vital importancia en la profundización del Proyecto político europeo, común a todos los Estados miembros.

\section{BIBLIOGRAFÍA CONSULTADA}

Alonso García, R.: Derecho comunitario, Derechos nacionales y Derecho europeo, Civitas.

Alonso GARCiA, R., en AA.Vv. Derechos fundamentales y Comunidades europeas, Edit. Civitas.

- Alonso García, R., "The General Provisions of The Charter of Fundamental Rights of the European Union", Jean Monet Working Paper 4/02.

- Alonso García, R.: "La Carta de los derechos fundamentales de la Unión Europea", en Gaceta Jurídica de la Unión Europea $\mathrm{N}^{\circ}$ 209, septiembre-octubre 2000 .

- ArezzA, L.: Le forme di rilevanza della Carta dei diritti Fondamentali dell'Unione Europea en La Difficile Costituzione europea ( dir. U. De Siervo), Il Mulino, Bologna, 2001.

- BECK, Qué es la globalización. Barcelona, Paidós. 1998, p. 186, vid. JÁuregui, G. (n. 85), p. 128

- Benhardt, R.: Encyclopedia of Public International Law, 5, Amsterdam Elsevier, 1983.

- Bering Lissberg, J.: "Does the EU Charter of Fundamental Rights Threaten the Supremacy of Community Law. Article 53 of the Charter. A Fountain of Law or Just an Inkblot?", Harvard Law School. The Jean Monnet Chair, Paper 010401, points 2 and 4).

- BesselinK, L. "Enfrapped by the Maximum Standard", CMLR 35 1998.

- Besselink, L.: "The member States, the National Constitution and the Scope of the Charter", Maastricht Journal of European and Comperative Law, 2001.

- Bobbio, N.: El futuro de la democracia, Plaza y Janés, 1985.

- Bradiey, AA.VV.: "Reflections on thee Human Rights Role of The European Parliament, both in Alston (Ed.)", The EU and Human Rights, OUP, 1999.

- Braibant, G. : La charte des droits fondamentaux de l'Union Européenne, Edit. Du Seuil, 2001.

- CançAdo TRindade, A.A.: "Retos y perspectivas de la protección internacional de los Derechos Humanos al inicio del siglo XXI", en El Derecho internacional de los derechos bumanos en el siglo XXI, Capítulo VIII. 
- CANOR, I.: "Primus inter pares. Who a the ultimate guardian of fundamental rights in Europe?", 12000, 25, ELRev, Feb.

- Carreau, D. : "Droit communautaire et droits nationaux: concurrence ou primauté? La contribution de l'arrêt Simmenthal?", Rev Europe, 1978.

- Carrillo Salcedo, J. A.: "Notas sobre el significado político y jurídico de la Carta de derechos fundamentales de la Unión Europea", en Revista de Derecho comunitario europeo. CEPC. Enero 2001.

- Castells, Manuel: El fin del milenio, Alianza, 1998.

- Cazor, K.: ponencia inédita sobre Multiculturalismo y orden global, Seminario sobre Globalización de la Universidad Austral de Chile, septiembre de 2003. En vías de publicación.

- Christiansen T. and Jørgensen K.E., "Negotiating Treaty Reform in the European Union.

- Constantinesco: "La Carta Europea de Derechos Fundamentales. Una visión desde Francia", en Anuario de derechos humanos nueva época, volumen 2, Instituto de Derechos Humanos. Facultad de Derecho Universidad Complutense, Madrid, 2001.

- Cox, R.: "Democracy in Hard Times", en: MCGREW (comp.), Globalization and Territorial Democracy.

- Cox, R.: «Global Restructuring: Making Sense of the Changing International Economy", en R. STUBBS, G. UNDERHILL (comps.), Political Economy and the Changing Global Order, Nueva York, 1994.

- Crossick, Stanley: "As the pace of the debate accelerates, provides a snapshot of the emerging consensus in the Convention", The European Policy Centre, February 2003 en bttp://www theepc.be

- DE Burca, G.: "The drafting of the European Union Charter of Fundamental Rights", 2001, 26, E.L. Rev. 126.

- De Carreras Serra, F.: "Por una Constitución europea", en REP, 90, 1995.

- De SChutTer. O.: "Les questions à résoudre. La protection des droits fondamentaux, un enjeu de la Convention pour l'avenir de l'Europe", en http://europa,eu.int/comm/justice_home/unit/charte/ fr/questions.html

- Diez-Hochleintner, J.: "La interdependencia entre el Derecho Internacional y el Derecho de la Unión Europea", en Cursos de Derecho Internacional de Victoria-Gasteiz, 1998.

- Diez-Hochleitner, J.: La posición del Derecho Internacional en el ordenamiento comunitario, Madrid 1998, pp. 59-72.

- Díez-Picazo Jiménez, L. M.: "Glosas a la nueva Carta de Derechos fundamentales de la Unión Europea”, en Tribunales de Justicia, 5, 2001.

- Erik O. Eriksen, John E. Fossum y Agustín J. Menéndez: "On constitution making and democratic legitimacy", introduction note on session ii http://www.arena.uio.no/events/conference2002/papers.html 
Fernández Gutiérrez, Mónica: “Aspectos fundamentales del sistema de integración de la Unión Europea. Referencias al MERCOSUR", en Revista de la Escuela de Derecho 2001, N², Universidad Católica de Temuco. Chile.

- FernÁndez Gutiérrez, Mónica: "Límites constitucionales sobre la aplicación del Derecho comunitario en el Sistema de Integración europeo. Algunas referencias a la Constitución chilena de 1980", Jornadas de Derecho Público, Revista de Derecho. Universidad Católica de Valparaíso, Chile, 2002.

- Fernández Sola, Natividad: "A quelle necessite juridique repond la negociation d'une charte des droits fondamentaux de Union Européenne?", en Revue du Marché Commun et de l'Union Européenne. N. 442, oct-nov, 2000.

- Ferrajoli, L: Derecho y Garantías, Trotta.

- Ferrajoli: "La conquista de América y la doctrina de la soberanía exterior de los Estados", en BERGALli, Roberto, y RESTA, Eligio: Soberanía: Un principio que se derrumba, Paidós, Barcelona, 1996.

- García de ENTerría, "La democracia y el lugar de la ley", REDA, 1996.

- García de Enterría, E. "El Proyecto de Constitución europea", en REDC, 45,1995.

- Giddens, A.: Consecuencias de la modernidad, Alianza, 1993.

- GIL IbÁÑ̃E, A. J.: El control y ejecución del Derecho comunitario, MAP, Instituto Nacional de Administraciones Públicas, Estudios jurídicos, Madrid, 1998

- Gosalbo Bono, Ricardo: "Reflexiones en torno al futuro de la protección de los derechos humanos en el marco del derecho Comunitario y del Derecho de la Unión: insuficiencias y soluciones...." Revista de Derecho Comunitario Europeo, Centro de Estudios Constitucionales, 1997.

- Grewe, C. (AA.Vv.): "Les conflits de formes entre Droit communautaire et Droits nationaux en matière de droits fondamentaux" (dir. S. Leclerc, J.F. Akandji-Kombé and M.J. Redor), Bruylant, Brussels, 1999 .

- Habermas, J.: La Constelación Posnacional, Edit. Paidós, 2000.

- Habermas, J.: "El valle de lágrimas de la globalización", en Revista Claves de la razón práctica, $\mathrm{N}^{\circ} 109,2001$.

- HARLOW C., Rawlings: Law and Adminitration, Butterworths, 1997; vid. Craig, P.: Administrative Law, Sweet and Maxwell, London, 1994. Vid. GIDDENS: (n. 4).

- Held, D.: La democracia global, Edit. Paidós, Estado y sociedad, 2002.

- Held, D.: "Democracy, the Nation State and the Global System", en Held (comp.): Political Theory Today, Cambridge, 1991.

- Himsworth, C. M. G., "In a State no Longer: The end of Constitutionalism?", en Public Law, 1996. 
- HoffmanN, Lars: "The Convention on the Future of Europe -Thoughts on the Convention Model", Jean Monnet Working Paper 11/02.

- Huntington, S: El choque de civilizaciones y la reconfiguración del orden mundial, Edit. Paidós, Estado y Sociedad, Barcelona, 2001.

- ISAAC, Guy: Manual de Derecho comunitario general, $4^{\mathrm{a}}$ edición, Editorial Ariel S.A., Barcelona.

- JÁuregui, G.: La Democracia Planetaria. Ediciones Nobel, 2000, p. 127.

- Jiménez Piernas, Carlos: "El Incumplimiento del derecho comunitario por los Estados miembros cuando median actos de particulares", en Revista de Derecho Comunitario Europeo, Vol.7, 2000.

- Kelsen, H.: Teoría General del Derecho y del Estado, Editorial Universidad Nacional Autónoma de México, 1979.

- KymlicKA, W.: Multicultural Citizenship, Oxford University Press, 1995.

- Lehuedé Chaparro, H.: La Supranacionalidad, Editorial Jurídica de Chile, 1966.

- LODGE, J.: "Intergovernmental Conferences and European Integration: Negotiating the Amsterdam Treaty", in International Negotiations, $\mathrm{N}^{\circ} 3,1998$.

- LÓPEZ AYLLÓN: El impacto de los instrumentos comerciales internacionales. El papel del derecho internacional en América. UNAM, México.

- Manin, PH.: Les communautes Européennes. L'Unión Europèenne. Droit institutionel, Editions Pedone, Paris, 1997.

- Martín PÉrez de NANClares, J.: El sistema de competencias de la Comunidad Europea. Germen iusinternacionalista versus vocación federal, Madrid 1997.

- Milward, A. L.: The european recue of the Nation-State, Berckley y Los Ángeles 1992.

- MuÑoz Machado, S.: El Estado, el derecho interno y la Comunidad Europea. Ed. Civitas, Madrid, 1986.

- O'BRIAN, R.: The end of the Geographie; Londres, Rotledge, 1992.

- Parejo Alfonso, Ortega Álvarez, Jiménez Blanco: Manual de

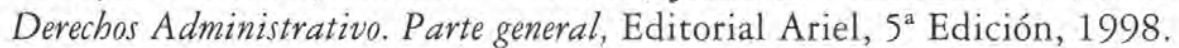

- Proyecto de Tratado constitucional, CONV. 724/03, 725/03, 810/03 en www.europa.eu.int

- Rodríguez Iglesias, Gil Carlos y Valle Gálvez, Alejandro: "El Derecho Comunitario y las relaciones entre el Tribunal de Justicia de las Comunidades Europeas, el Tribunal Europeo de Derechos Humanos y los Tribunales Constitucionales Nacionales, Centros de Estudios Políticos y Constitucionales, año 1997.

- Rosseau, J. Social contract, Harmondsworth, 1968.

- Rubio Llorente, F.: El constitucionalismo de los Estados integrados de Europa, Fundación Ortega y Gasset, Madrid 1996. 
- Rodríguez Iglesias, G. C.: "Consideraciones sobre la formación de un Derecho Europeo”, en CJ, N²00 abril/mayo 1999.

- RosenaU, J: Turbulence in world politics, 1990, Harverser, NY, Londres, Harvester Whweatsheaf, 1990.

- Rubio Llorente: "Mostrar los derechos sin destruir la Unión", Revista Española de Derecho Constitucional, Año $22 \mathrm{~N}^{\circ}$ 64, 2002.

- Ruffilli, R.: "Crisis dello stato moderno: ideologie e istituzione", Il Mulino, Bologna, 1984.

- Schwarze Jurgen: "Perspectivas constitucionales de la Unión Europea ante la próxima CIG de 2004. Comunicación 7 noviembre de 2001", Sppech, Colegio de Eméritos, Madrid.

- Simon, D. "La Communauté de Droit", F. Sudre et H. LABAyle (dir.), en Réalité et perspectives du droit communautaire des droits fondamentaux, BRUYLANT, Bruxelles, 2000.

- Simon, D.: "La Communauté de Droit". Frédéric SuDre et Henri LABAYLE (dir.) En Réalité et perspectives du droit communautaire des droits fondamentaux, Bruylant Bruxelles, 2000.

- Söderman, Jacob: "European Ombudsman. The Convention, the Charter and the Remedies", EPC Dialogue: The Convention and the Charter of Fundamental Rights.The European Policy Centre, Brussels, 25 February 2003 http://www.euro-ombudsman.eu.int/speeches/fr

- Solana, J.: Europa y su futuro, Ed. Fundación, conferencia anual Francisco Fernández Ordóñez, Madrid 2000.

- TAYlOR, P.: "Elements of Supranationalism", TAYlOR, P., GROOM, A. J. R.: International organizations, A conceptual approach, London, Pinter 1978.

- Teló, Mario, AA.Vv.: "Democratie et construction européenne", Direction Mario Teló, Editions de l'Université de Bruxelles, Études Européenes. Democratie internationale et democratie supranationale en Europe.

- UN., United Nations Conference on the Law of Treaties between States and International Organizations or between International Organizations (Viena, 1986) - Official Records, vol. 1, N.Y., U.N., 1995 (intervención de A.A. CANÇADO TRINDADE, también reproducida en: 69171 Boletim da Sociedade Brasileira de Direitto International (1987-1989).

- Vallespin, F.: El futuro de la política, Taurus, 2000.

- VON BOGDANDY, Armin: "El orden competencial vertical de la UE", ponencia en el Colegio de Eméritos de Madrid, 2001.

- Weiler, J.H.H, AA.Vv.: "Democratie et construction européenne", Direction Mario Teló, Editions de l'Université de Bruxelles, Études Européenes Ideaux et construction européenne.

- WeILER, J.H.H. 1999: The Constitution of Europe: "Do the New Clothes Have an Emperor?" and other essays on European integration. Cambridge: Cambridge University Press. 
- Weiler, J.H.H. 2000: Federalism and Constitutionalism: Europe's Sonderweg, Harvard Jean Monnet Working Paper 10/00.

- Weizsacker, R.; Dehaene, J.L. y Simon, D: "Las implicaciones institucionales de la ampliación", en Revista de Derecho comunitario Europeo, número 6, 1999.

- YATAGANAS "The Treaty of Nice: The Sharing of Power and the Institutional Balance in the European Union - A Continental Persepctive", in European Law Journal, Vol 7, N ${ }^{\circ}$ 3, 2001.

- Zagrebelsky, G.: "El derecho dúctil. Ley, derechos y justicia", Edit. Trotta. 